\title{
METABOLÔMICA MICROBIANA: INOVAÇÕES E APLICAÇÕES
}

\author{
João Raul Belinato ${ }^{\mathrm{a}, \mathrm{b}}$, Jaqueline Moraes Bazioli ${ }^{\mathrm{a}, \mathrm{c}}$, Alessandra Sussulini ${ }^{\mathrm{a}, \mathrm{b}}$, Fabio Augusto ${ }^{\mathrm{a}, \mathrm{b}}$ e Taícia Pacheco Filla,*, (1) \\ ${ }^{a}$ Instituto de Química, Universidade Estadual de Campinas, 13083-970 Campinas - SP, Brasil \\ 'Instituto Nacional de Ciência e Tecnologia de Bioanalítica, 13083-970 Campinas - SP, Brasil \\ ${ }^{c}$ Faculdade de Ciências Farmacêuticas, Universidade Estadual de Campinas, 13083-871 Campinas - SP, Brasil
}

Recebido em 07/12/2018; aceito em 09/01/2019; publicado na web em 27/02/2019

\begin{abstract}
MICROBIAL METABOLOMICS: INNOVATIONS AND APPLICATIONS. Over the past few years, metabolomics has been employed in a broad range of applications in different research fields. Microbial metabolomics has been applied in several microbiological areas, such as identification of microorganisms, cell mutations, functional gene approach, identification of unique metabolic pathways and microbial engineering, leading to a better understanding of the global metabolism and metabolic regulation of certain systems. Metabolites produced by microorganisms constitute a large promising group with diverse applications; however, most of these systems are still unknown and underexplored. In this context, the overall analysis of metabolites involved in a biological system can be used to discover potential biomarkers or specific metabolic changes due to a biological phenomenon studied. In this sense, this review aims to understand the main challenges faced by each step of the workflow in the metabolic analysis of microorganisms and how these difficulties have been overcome. A critical analysis of the articles published within the last five years will be accomplished in this paper to understand how these studies have contributed to the microbial metabolomics research. Moreover, major trends observed in this area will be highlighted here in order to guide readers interested in microbial metabolomics in their future researches.
\end{abstract}

Keywords: metabolomics; metabolomics workflow; microorganism; sample preparation; metabolomics analysis.

\section{INTRODUÇÃO}

Ao longo dos últimos anos, a metabolômica tem desempenhado um papel essencial na pesquisa básica para elucidar os efeitos ambientais, ${ }^{1}$ entender as funções dos genes, ${ }^{2}$ e a definição dos processos celulares ${ }^{3}$ em busca de uma melhora na qualidade de vida humana. Ela pode ser definida como a análise abrangente (qualitativa e quantitativa) de metabólitos, tendo como objetivo principal reunir a maior quantidade possível de informações metabólicas de um organismo ou sistema biológico. ${ }^{4,5} \mathrm{Na}$ análise metabolômica o principal interesse está nas moléculas de baixa massa molar $(<1000 \mathrm{Da})$, que suportam funções vitais e participam de reações metabólicas, sendo essa informação usada para obter uma melhor compreensão das vias bioquímicas. ${ }^{6}$

Os metabólitos são classificados como produtos finais dos processos celulares e seus níveis nos sistemas biológicos podem ser considerados como a resposta final às mudanças genéticas, ambientais ou decorrentes de alguma patologia e/ou tratamento. ${ }^{7}$ Os principais desafios na análise química desses compostos estão relacionados com a complexidade química e a heterogeneidade, requerendo protocolos específicos quanto ao preparo de amostras, decisões sobre a técnica de análise mais adequada, assim como a estratégia mais eficiente de processamento e interpretação dos dados analíticos. ${ }^{8}$

Quando se tratam de micro-organismos, os estudos no âmbito metabolômico têm contribuído para a descoberta de caminhos metabólicos únicos e interações regulatórias, sendo essas descobertas extremamente úteis para a compreensão do metabolismo global das células. ${ }^{5,9}$ A metabolômica microbiana tem sido aplicada em vários campos microbiológicos, como identificação de micro-organismos, ${ }^{10}$ mutações celulares, ${ }^{11}$ pesquisa de genes funcionais ${ }^{12}$ e identificação de vias metabólicas. ${ }^{13}$ Quando comparada a outros estudos, a principal desvantagem da metabolômica de micro-organismos está na alta complexidade dos metabólitos ainda pouco explorados e, em

*e-mail: taicia@iqm.unicamp.br alguns casos, de difícil identificação. Além disso, a separação dos metabólitos intracelulares e extracelulares em micro-organismos não é uma tarefa trivial. ${ }^{5}$

Apesar do avanço significativo em instrumentação analítica e no aumento do número de bancos de dados envolvendo metabólitos microbianos, muitos desafios envolvidos em metabolômica microbiana ainda precisam ser superados. Dessa forma, este artigo de revisão visa compreender os principais desafios enfrentados por cada etapa do fluxo de trabalho, e como essas dificuldades vêm sendo contornadas com base na literatura recente. Além disso, as principais tendências observadas nessa área serão destacadas aqui, a fim de orientar os leitores interessados em metabolômica microbiana em suas futuras pesquisas.

\section{DEFINIÇÕES EM METABOLÔMICA}

Usualmente, duas abordagens principais e complementares são usadas em investigações metabolômicas: perfil metabólico (do inglês, metabolic profiling) e impressão digital metabólica (do inglês, metabolic fingerprinting. Além disso também são encontrados os termos análise alvo (do inglês, targeted metabolomics) e análise global (do inglês, untargeted metabolomics), onde, a fim de padronizar as discussões ao longo deste trabalho de revisão, essas serão as abordagens adotadas. A análise alvo concentra-se na análise de um grupo de metabólitos, seja esse grupo relacionado à uma via metabólica específica ou à uma classe de compostos. ${ }^{14,15} \mathrm{Na}$ maioria dos casos, a análise alvo é uma abordagem orientada por hipóteses, e não uma abordagem para geração de hipóteses. Dessa forma, métodos analíticos são desenvolvidos visando a análise de compostos específicos. Por outro lado, os avanços tecnológicos nos últimos anos têm impulsionado uma expansão na quantificação simultânea de um amplo número de substâncias. ${ }^{16,17} \mathrm{~A}$ abordagem global está relacionada à análise qualitativa do maior número possível de metabólitos, pertencentes a diferentes classes químicas, encontrados em um determinado sistema biológico 
alvo e é geralmente utilizada como uma ferramenta de triagem para discriminar amostras de diferentes estados biológicos ou origem. Nesse tipo de abordagem, etapas de preparação da amostra podem ser simplificadas ou até mesmo eliminadas. ${ }^{18} \mathrm{~A}$ principal vantagem da abordagem global em relação à abordagem direcionada é que a primeira permite que novas áreas do metabolismo sejam identificadas. ${ }^{14,15,19}$ Ainda, análises do tipo exometabolômica (do inglês, footprinting) têm sido empregadas para se referir aos estudos dos metabólitos excretados por uma célula (metaboloma extracelular) ou determinado sistema. ${ }^{15,17}$

\section{FLUXOGRAMA DE TRABALHO APLICADO A ANÁLISES DE MICRO-ORGANISMOS}

A metabolômica microbiana tem se desenvolvido rapidamente nos últimos anos e esse desenvolvimento foi paralelizado e apoiado por avanços importantes em instrumentação analítica e tecnologias, em particular métodos cromatográficos e de espectrometria de massas, juntamente com novas e poderosas ferramentas computacionais. ${ }^{20-22}$ No desenvolvimento desses estudos, sejam eles globais ou alvo-orientados, recomenda-se seguir uma série de etapas, que estão apresentadas resumidamente na Figura 1. Tais abordagens podem ser aplicadas em ambos os tipos de estudo, requerendo particularidades experimentais inerentes ao tipo de aplicação.

De forma geral, a sequência de trabalho constitui-se da etapa de preparo de amostra, que envolve principalmente o quenching e a extração de metabólitos, análise instrumental, processamento e análise dos dados. Para entender melhor cada uma dessas etapas aplicadas às análises de micro-organismos, elas serão descritas individualmente buscando exemplos de aplicações na área microbiológica, além de considerar as devidas particularidades para cada abordagem quando necessário.

A definição do problema biológico a ser estudado é a primeira etapa no desenvolvimento do estudo, para a determinação do tipo de abordagem empregada (global ou alvo). Após essa escolha, as etapas de planejamento experimental e análise química são delineadas e o experimento metabolômico é conduzido. ${ }^{15,23,24}$ A partir daí, segue-se para o fluxograma de trabalho propriamente dito.

\section{Amostragem e preparo de amostras}

Os procedimentos de amostragem e preparo de amostras são componentes vitais de qualquer estudo metabolômico, pois os metabólitos provenientes dos micro-organismos podem sofrer variações metabólicas rápidas durante as etapas de preparo da amostra (geralmente em 1-2 s), por isso, é crucial que essa coleta e manipulação da amostra seja rápida. ${ }^{5}$ Além disso, outro passo importante é a realização do quenching metabólico, que visa a interrupção rápida da atividade enzimática através do uso de solventes específicos e baixa temperatura, buscando manter a célula ou o organismo intacto em todos os momentos. ${ }^{5}$ A escolha do quenching adequado depende principalmente do tipo de micro-organismo a ser investigado e, em alguns casos, da adequação para os metabólitos de interesse..$^{25}$

Como a maioria dos estudos de metabólitos microbianos envolve um procedimento de extração, em grande parte dos casos, o quenching metabólico é realizado simplesmente como a etapa de congelamento da biomassa em baixas temperaturas e, em seguida, separada do meio extracelular por centrifugação, seguindo-se para o passo de lavagem. ${ }^{26-31}$ Para uma descrição válida do metaboloma intracelular as etapas de lavagem e quenching metabólico são cruciais. A lavagem deve efetivamente remover os componentes do meio extracelular e o quenching deve interromper as atividades metabólicas dentro da célula. Portanto, é importante avaliar a eficiência dos solventes tanto na etapa de lavagem quanto na etapa do quenching. ${ }^{32}$

No procedimento de extração, a etapa de lavagem é uma prática comum para a remoção de metabólitos encontrados no exterior da célula. ${ }^{33}$ Em um estudo sobre parâmetros que afetam a detecção e quantificação de classes de metabólitos envolvidos na extração metabolômica, os autores relataram que, além dos fatores temperatura e pH, a lavagem é uma prática comum e de extrema importância na remoção de metabólitos extracelulares, melhorando nesses casos a relação sinal-ruído. ${ }^{34}$ Os trabalhos realizados até o presente momento têm descrito muito pouco sobre as etapas de quenching e lavagem, sendo que muitas vezes não há uma otimização clara desses procedimentos ou mesmo testes de controle para avaliar a perda de metabólitos pela ausência ou realização não significativa desses procedimentos. Entretanto, a avaliação e otimização dessas

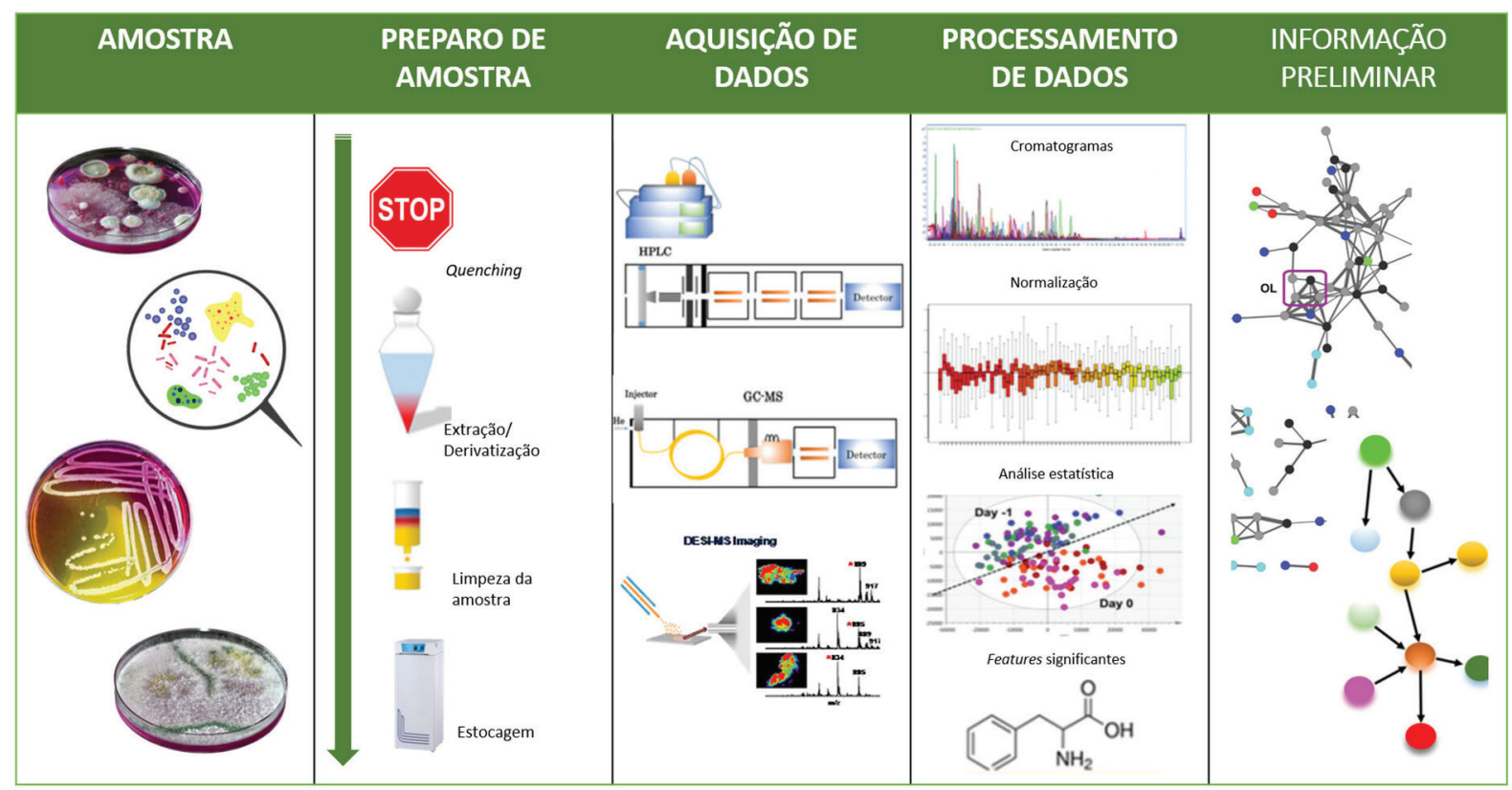

Figura 1. Fluxo de trabalho para abordagem metabolômica não direcionada. Adaptado de Khoomrung, et al. 2017. ${ }^{23}$ Copyright 2017, com autorização da revista mediante as normas de open-access 
etapas poderiam aumentar a confiabilidade dos estudos metabolômicos obtidos. Em alguns estudos, esse procedimento é realizado em combinação com a etapa de extração, onde utilizam-se solventes ou misturas de solventes à baixa temperatura no processo de extração. ${ }^{35-38}$ Além disso, mediante a importância desse procedimento, em alguns casos também são realizados testes com diferentes tipos de quenching a fim de avaliar o melhor método a ser utilizado.

Um estudo de perfil metabólico utilizando a levedura Pichia pastoris empregou diferentes metodologias de quenching, demonstrando, assim, duas abordagens para metabólitos extracelulares e intracelulares. ${ }^{39} \mathrm{Na}$ avaliação dos metabólitos extracelulares, as amostras foram rapidamente centrifugadas e decantadas antes de serem congeladas em gelo seco. Com relação à avaliação dos metabólitos intracelulares, foi utilizado um procedimento de quenching total (células + meio de cultura) com $60 \%$ de metanol aquoso e bicarbonato de amônio para interromper o metabolismo. ${ }^{39} \mathrm{~A}$ mistura metanol-água à baixa temperatura (aproximadamente $-40{ }^{\circ} \mathrm{C}$ ) é um dos procedimentos mais relatados na literatura, ${ }^{40}$ inclusive nos estudos lipidômicos, ${ }^{41,42}$ sendo aplicado também em estudos metabólicos do fungo Fusarium oxysporum,,$^{43}$ e da bactéria Gluconacetobacter xylinus, ${ }^{44}$ dentre outros. ${ }^{45,46} \mathrm{~A}$ mistura tem se apresentado extremamente eficiente nesses estudos alcançando ótimos resultados, mas ainda vale ressaltar que os experimentos simples de otimizações podem viabilizar uma escolha ainda mais confiável do método empregado.

Após o quenching metabólico, frequentemente é realizada a separação dos metabólitos extracelulares dos intracelulares, dependendo da abordagem empregada. ${ }^{31}$ Para identificar e quantificar metabólitos intracelulares, é necessário extrair esses compostos do compartimento intracelular protegido pela membrana celular. Isso é alcançado usando solventes de extração (orgânicos, inorgânicos não aquosos ou uma mistura dos dois), que tornam a membrana celular porosa ou permeável, permitindo a penetração dos solventes no meio intracelular e uma maior recuperação desses metabólitos intracelulares ${ }^{47}$ Por outro lado, os metabólitos presentes no ambiente extracelular são originalmente parte da composição do meio de cultura, compostos secretados pelas células ou produto das lises celulares e, por isso, são mais facilmente extraídos. ${ }^{2.5}$

A extração dos metabólitos é uma etapa de extrema importância na metabolômica microbiana, embora em alguns casos acabe sendo negligenciada. ${ }^{25}$ Em geral, a etapa de extração é dependente da estratégia do estudo metabolômico empregado e do tipo de análise. ${ }^{48}$ Para análises não direcionadas, por exemplo, o objetivo é extrair o maior número de metabólitos de muitas classes químicas de forma quantitativa e não tendenciosa, com perdas mínimas de metabólitos. Portanto, as amostras são analisadas priorizando o preparo de amostras mínimo, como precipitação de proteínas, remoção de sais, filtração e diluição. ${ }^{15,48}$

A avaliação global dos metabólitos extracelulares geralmente envolve somente etapas de extração do meio extracelular e diluições. Para os metabólitos intracelulares, usualmente são empregados procedimentos preliminares que possibilitem a lise celular e em seguida o uso de extrações líquido-líquido a fim de minimizar a distinção de classes químicas para a análise global ${ }^{49,50} \mathrm{e}$, em alguns casos, utilizam-se etapas de agitação e centrifugação. ${ }^{35,37,51-54}$ Em geral, estudos recentes têm utilizado esse tipo de extração variando os solventes empregados, dependendo principalmente do micro-organismo em estudo. A Tabela 1 sumariza alguns dos principais estudos encontrados em análises metabolômicas de micro-organismos, destacando os principais solventes e proporções utilizadas, bem como outros sistemas de extração.

No que se refere aos sistemas extratores modernos, plataformas microfluídicas foram empregados em análises metabolômicas de micro-organismos a fim de miniaturizar as etapas de extração. O sistema desenvolvido pelos autores ${ }^{60}$ utiliza um sistema bifásico aberto

Tabela 1. Resumo de algumas aplicações e métodos recentes usados na análise metabolômica de micro-organismos

\begin{tabular}{|c|c|c|c|c|}
\hline Micro-organismos & Descrição & Preparo de Amostra & Análises Metabolômicas & Referência \\
\hline $\begin{array}{l}\text { Cunninghamella } \\
\text { echinulata }\end{array}$ & $\begin{array}{l}\text { Avaliação das respostas em diferentes níveis de } \\
\text { morfologia celular, bioquímica e fisiológica de mi- } \\
\text { croorganismos em exposição à compostos tóxicos. }\end{array}$ & $\begin{array}{c}\text { Extração com a mistura } \\
\text { (Acetonitrila:Água, 80:20) }\end{array}$ & LC-MS & {$[55]$} \\
\hline Bactérias anammox & $\begin{array}{l}\text { Informações para capturar o metabolismo ideal de } \\
\text { anammox consortia e acelerar o cultivo bacteriano } \\
\text { ou a inicialização de reatores para tratamento de } \\
\text { águas residuais. }\end{array}$ & $\begin{array}{c}\text { Extração com Metanol a - } \\
80^{\circ} \mathrm{C}\end{array}$ & LC-Orbitrap-MS & {$[101]$} \\
\hline
\end{tabular}

Metarhizium

brunneum

Os dados metabolômicos demonstraram que a presença de ametrina na cultura fúngica induziu estresse oxidativo e graves rupturas no metabolismo de carbono e nitrogênio.

O estudo descreve que, em resposta a temperaturas frias, a Pseudomonas syringae PDD-32b-74

Pseudomonas syringae demonstra inúmeras modificações no seu metabolismo a fim de neutralizar os impactos das baixas temperaturas.

Escherichia coli $\quad$ Efeitos de meios de cultura pobres vs. meios come Saccharomyces plexos nos perfis de metabólitos de Escherichia coli cerevisiae e Saccharomyces cerevisiae.

Estudo metabolômico que fornece uma plataforma abrangente para caracterizar a diversidade microbiana e sua aplicação na produção de biomateriais.

Análise metabólica do desenvolvimento de biofilme fúngico e do mecanismo de detecção do quórum de ácido araquidônico.

Este estudo demonstra que o dispositivo de cocultura utilizado na metabolômica facilitariam a investigação de interações mediadas quimicamente pela natureza, bem como a descoberta de produtos naturais.

Cladosporium sp
Bacillus subtilis
Extração com a mistura

(Acetonitrila:Água 2:98 v/v)

LC-MS e LC-MS/MS

Extração com a mistura $\left(\mathrm{H}_{2} \mathrm{O}: \mathrm{MeOH}: \mathrm{CH}_{3} \mathrm{CN}, 1: 2: 2\right)$

LC-MS, LC-MS/MS e NMR

Extração com a mistura

(Acetonitrila:Água-1:1)

GC-TOF-MS e LC-MS

Extração líquido-líquido com Acetato de Etila

GC-MS e LC-MS/MS

Extração com Metanol à frio

${ }^{1} \mathrm{H}$ NMR

Dispositivo de co-cultura desenvolvido pelos autores seguido de extração líquido-

UHPLC-ESI-HRMS líquido 
Tabela 1. Resumo de algumas aplicações e métodos recentes usados na análise metabolômica de micro-organismos (cont.)

\begin{tabular}{|c|c|c|c|c|}
\hline Micro-organismos & Descrição & Preparo de Amostra & Análises Metabolômicas & Referência \\
\hline $\begin{array}{l}\text { Clostridium } \\
\text { acetobutylicum }\end{array}$ & $\begin{array}{l}\text { Este estudo representa uma adição significativa } \\
\text { ao corpo de trabalho demonstrando a existência e } \\
\text { importância de policetídeos em anaeróbios, além } \\
\text { da estratégia de manipulação do metabolismo } \\
\text { secundário de um organismo para melhorar car- } \\
\text { acterísticas relevantes nas aplicações industriais. }\end{array}$ & $\begin{array}{c}\text { Extração líquido-líquido com } \\
\text { Acetato de Etila em pequena } \\
\text { escala }\end{array}$ & LC-HRMS & {$[57]$} \\
\hline Escherichia coli & $\begin{array}{l}\text { Este trabalho mensura e descreve a atividade in vivo } \\
\text { e estabilidade da ciclo-hexanona mono-oxigenase de } \\
\text { Acinetobacter sp. NCIMB } 9871 \text { (CHMO), modelo } \\
\text { Baeyer - Villiger mono-oxigenase, no hospedeiro } \\
\text { recombinante Escherichia coli. }\end{array}$ & $\begin{array}{l}\text { Extração líquido-líquido com } \\
\text { diversas misturas de solventes }\end{array}$ & LC-MS/MS & [98] \\
\hline Thermus filiformi & $\begin{array}{l}\text { Estratégias de adaptação térmica da bactéria ex- } \\
\text { tremófila Thermus filiformis baseada em análises } \\
\text { multi-ômicas. }{ }^{54}\end{array}$ & $\begin{array}{c}\text { Extração com a mistura } \\
\text { (MTBE:Metanol:Água 3:1:1) }\end{array}$ & GC-TOF-MS & {$[60]$} \\
\hline Streptomyces sp. & $\begin{array}{l}\text { Descoberta direcionada por estresse de um anti- } \\
\text { biótico crítico produzido por Streptomyces sp. da } \\
\text { fonte hidrotermal de Kueishantao através de uma } \\
\text { estratégia metabolômica integrada. }\end{array}$ & $\begin{array}{l}\text { Extração líquido-líquido com } \\
\text { Acetato de Etila }\end{array}$ & LC-MS e ${ }^{1} \mathrm{H}$ NMR & {$[42]$} \\
\hline $\begin{array}{l}\text { R. solanacearum e } \\
\text { A. flavus to }\end{array}$ & $\begin{array}{l}\text { Este trabalho determinou se a comunicação química } \\
\text { de } R \text {. solanacearum direciona a um desenvolvimento } \\
\text { simbiótico de consórcios polimicrobianos. }\end{array}$ & Extração com Acetonitrila & MALDI-TOF & {$[56]$} \\
\hline Pseudomonas sp. & $\begin{array}{l}\text { Através da análise de } 370 \text { extratos de Pseudomonas } \\
\text { associadas ao trigo, demonstrou-se o conhecimento } \\
\text { detalhado de dados metabolômicos complexos. }\end{array}$ & $\begin{array}{l}\text { Extração líquido-líquido (Ac- } \\
\text { etato de Etila:Metanol 1:1) }\end{array}$ & LC-MS/MS & {$[36]$} \\
\hline $\begin{array}{l}\text { Aspergillus fumigatus, } \\
\text { P. aeruginosa } \mathrm{e} \\
\text { R. solanacearum }\end{array}$ & $\begin{array}{l}\text { Demonstrar o potencial da classe de sistemas mi- } \\
\text { crofluídicos para estudar a comunicação entre os } \\
\text { fungos e as bactérias. }\end{array}$ & $\begin{array}{l}\text { Extração utilizando plataforma } \\
\text { em microescala e solventes } \\
\text { de alto ponto de ebulição } \\
\text { (clorofórmio, 1-pentanol e } \\
\gamma \text {-caprolactona) }\end{array}$ & LC-MS e LC-MS/MS & {$[61]$} \\
\hline $\begin{array}{l}\text { Candida albicans e } \\
\text { Staphylococcus aureus }\end{array}$ & $\begin{array}{l}\text { Os resultados da metabolômica não direcionada sug- } \\
\text { eriram uma produção significativa de componentes } \\
\text { de biossíntese de parede celular e o consumo de } \\
\text { aminoácidos essenciais. }\end{array}$ & $\begin{array}{l}\text { Extração líquido-líquido } \\
\left(\mathrm{CHCl}_{3}: \mathrm{MeOH}: \mathrm{H}_{2} \mathrm{O} \text { 1:3:1) }\right.\end{array}$ & GC-Orbitrap & {$[58]$} \\
\hline $\begin{array}{l}\text { Gluconacetobacter } \\
\text { xylinus }\end{array}$ & $\begin{array}{l}\text { Perfil metabólico associado à rede metabólica } \\
\text { demonstrando diferenças em Gluconacetobacter } \\
\text { xylinus de culturas estáticas e agitadas. }\end{array}$ & $\begin{array}{c}\text { Extração com a mistura de } \\
\text { solventes (Metanol: } \mathrm{H}_{2} \mathrm{O} \text { 2:1) }\end{array}$ & GC-MS & {$[50]$} \\
\hline $\begin{array}{l}\text { Burkholderia } \\
\text { pseudomallei }\end{array}$ & $\begin{array}{l}\text { Avaliação do perfil metabólico de Burkholderia } \\
\text { pseudomallei para identificação de biomarcadores } \\
\text { específicos, incluindo o 4-metil-5-tiazoleetanol e } \\
\text { uma via única de degradação da tiamina. }\end{array}$ & $\begin{array}{c}\text { Extração com a mistura de } \\
\text { solventes }\left(\mathrm{H}_{2} \mathrm{O}: \text { Metanol:ACN }\right. \\
1: 2: 2)\end{array}$ & LC-MS e LC-MS/MS & {$[67]$} \\
\hline Campylobacter jejuni & $\begin{array}{l}\text { Este estudo mostra que a plataforma metabolômica } \\
\text { baseada em UHPLC-MS é uma ferramenta prom- } \\
\text { issora e valiosa para gerar novos insights sobre o } \\
\text { mecanismo resistente à medicamentos de Campy- } \\
\text { lobacter jejuni. }\end{array}$ & $\begin{array}{c}\text { Extração com a mistura de } \\
\text { solventes (100\% MeOH a frio, } \\
\text { MeOH/Clorofórmio; 2:1, e } \\
\left.\text { ACN/ } \mathrm{H}_{2} \mathrm{O} ; 50: 50\right)\end{array}$ & LC-MS & {$[43]$} \\
\hline Lysobacter sp. & $\begin{array}{l}\text { Estudo dos genomas das espécies de Lysobacter } \\
\text { em combinação com seu perfil metabólico, for- } \\
\text { nece novos insights sobre o potencial genômico e } \\
\text { metabólico desse gênero bacteriano pouco estudado } \\
\text { e versátil. }\end{array}$ & Micro-organismo intacto & MALDI-Imageamento & {$[111]$} \\
\hline Salinispora arenicola & $\begin{array}{l}\text { Estudo de metabólitos secundário bacteriano } \\
\text { marinho e produção de antibióticos em Salinispora } \\
\text { arenicola. }\end{array}$ & $\begin{array}{l}\text { Extração líquido-líquido com } \\
\text { Acetato de etila }\end{array}$ & UHPLCQTOF-MS & {$[68]$} \\
\hline Streptomyces spp. & $\begin{array}{l}\text { Classificação quimiotaxonômica baseada em me- } \\
\text { tabolômica de Streptomyces spp. e sua correlação } \\
\text { com atividade antibacteriana. }\end{array}$ & Extração com Metanol & $\begin{array}{c}\text { UHPLC-QTOF-MS e LC-ESI- } \\
\text { MS/MS }\end{array}$ & {$[53]$} \\
\hline Pseudomonas putida & $\begin{array}{l}\text { Possíveis marcadores para o crescimento de } P . p u \text { - } \\
\text { tida, com e sem exposição ao Fe sólido e solúvel, } \\
\text { foram identificados a partir de diversas classes } \\
\text { químicas de metabólitos incluindo nucleobases, nu- } \\
\text { cleosídeos, dipeptídeos, tripeptídeos, aminoácidos, } \\
\text { ácidos graxos, açúcares e fosfolipídios. . }\end{array}$ & Extração com Metanol & LC-QTOF-MS & {$[136]$} \\
\hline Mycobacterium spp. & $\begin{array}{l}\text { Determinação de alterações metabólicas associadas } \\
\text { ao crescimento. }\end{array}$ & $\begin{array}{l}\text { Otimização utilizando diferen- } \\
\text { tes proporções de solventes }\end{array}$ & LC-MS e GC-MS & [51] \\
\hline
\end{tabular}


Tabela 1. Resumo de algumas aplicações e métodos recentes usados na análise metabolômica de micro-organismos (cont.)

\begin{tabular}{llcc}
\hline Micro-organismos & Descrição & Preparo de Amostra & Análises Metabolômicas \\
\hline & Análise metabolômica e transcriptômica da resposta & Extração com a mistura & \\
Xanthomoncia & \\
& do arroz ao microrganismo bacteriano Xanthomonas & (Água:Acetonitrila:Isopropanol, GC-TOF-MS e LC-TOF-MS \\
& oryzae. & $2: 3: 3$ ) & \\
\hline
\end{tabular}

Pseudomonas

aeruginosa,

Burkholderia

cenocepacia,

Haemophilus Perfil de compostos orgânicos voláteis para difeinfluenzae, $\quad$ renciar bactérias associadas às infecções pulmoStenotrophomonas nares. ${ }^{55,59}$

HS-SPME - 50/30 $\mu \mathrm{m}$ DVB/CAR/PDMS

GC×GC-TOF-MS

maltophilia,

Streptococcus

pneumoniae e

Streptococcus milleri

Identificação de biomarcadores específicos para a

A. fumigatus $\quad$ resposta de hipóxia fúngica e o estabelecimento do método de diagnóstico de aspergilose invasiva por

\begin{tabular}{ll} 
& $\begin{array}{l}\text { método de diagnóstico de aspergilose invasiva por } \\
\text { respiração. }\end{array}$ \\
\hline Identificação de compostos voláteis produzidos
\end{tabular}

Klebsiella pneumoniae $\begin{aligned} & \text { pela bactéria Gram-negativa patogênica Klebsiella } \\ & \text { pneumoniae (ATCC 13883) durante o crescimento }\end{aligned}$ in vitro. \begin{tabular}{ll}
\hline M. parvicella & $\begin{array}{l}\text { Avaliação da influência da composição de água } \\
\text { residuárias em bactérias filamentosas. }{ }^{57}\end{array}$
\end{tabular} Investigação do efeito do óleo de cravo e seus

E. coli principais constituintes como agentes bactericídas no perfil metabólico global da bactéria $E$. coli por meio de alterações metabólicas.

C. difficile Caracterização das moléculas voláteis produzidas por uma cepa epidêmica de $C$. difficile.

Investigação do perfil metabólico para determinar as alterações que ocorreram durante a deterioração

L. buchneri do pepino fermentado anaeróbio por L. buchneri LA1147 e durante a reprodução da deterioração com microbiota natural.

\begin{tabular}{ll}
\hline Memnoniella sp. & $\begin{array}{l}\text { Determinação dos metabólitos voláteis de fungos } \\
\text { saprotróficos. }\end{array}$ \\
\hline $\begin{array}{l}\text { Saccharomyces } \\
\text { cerevisiae }\end{array}$ & $\begin{array}{l}\text { Avaliação de diferentes metabólitos voláteis de } \\
\text { Saccharomyces cerevisiae e a variabilidade entre } \\
\text { as cepas. }\end{array}$ \\
\hline
\end{tabular}

Micro-organismos aeróbicos
Triagem do nível de contaminação microbiana e ácaro em cereais e grãos de café usando compostos orgânicos voláteis. ${ }^{58}$
HS-SPME - 50/30 $\mu \mathrm{m}$ DVB/CAR/PDMS

GC×GC-TOF-MS

[62]

HS-SPME - 50/30 $\mu \mathrm{m}$

DVB/CAR/PDMS

GC×GC-TOF-MS

SPME - $100 \mu \mathrm{m}$ PDMS

GC $\times$ GC-Q-MS

[63]

HS-SPME - 50/30 $\mu \mathrm{m}$

DVB/CAR/PDMS

GC×GC-TOF-MS e

UHPLC-MS

[75]

HS-SPME - 50/30 $\mu \mathrm{m}$

DVB/CAR/PDMS

GC×GC-TOF-MS

[76]

HS-SPME - 50/30 $\mu \mathrm{m}$

DVB/CAR/PDMS

GC $\times$ GC-TOF-MS

HS-SPME - 50/30 $\mu \mathrm{m}$

DVB/CAR/PDMS

GC $\times$ GC-Q-MS

[72]

HS-SPME - 50/30 $\mu \mathrm{m}$

DVB/CAR/PDMS

GC×GC-TOF-MS

[77]

HS-SPME - 85 mm (PA),

$100 \mathrm{~mm}$ (PDMS), $65 \mathrm{~mm}$

(PDMS/DVB) and 50/30 $\mathrm{mm}$

GC $\times$ GC-TOF-MS

(DVB/CAR/PDMS)

Acinetobacter spp., coagulase-negative Staphylococcus, $e$ Proteus mirabilis

Identificação de "impressões digitais" metabólicas voláteis específicas de patógenos para a rápida identificação de organismos causadores de doenças, diretamente de bioespécies de pacientes ex vivo ou de culturas in vitro. ${ }^{59}$
HS-SPME - 50/30 $\mu \mathrm{m}$ DVB/CAR/PDMS
$[65]$ em que o solvente orgânico é guiado sobre um ambiente de cultura microbiana, permitindo a extração integrada e passiva de metabólitos. O dispositivo foi aplicado em análises de metabólitos provenientes de diversos fungos e bactérias, possibilitando também a avaliação de co-culturas. Esse tipo de abordagem para extração de metabólitos miniaturizada parece ser uma tendência na área, uma vez que facilita a exploração de microambientes de cultura e possibilita a utilização de solventes orgânicos incomuns para o isolamento de metabólitos o que vem a ser uma grande vantagem quando comparado aos métodos clássicos de extração líquido-líquido. ${ }^{60}$

Nas análises alvo-orientadas, a extração deve favorecer a recuperação quantitativa das espécies químicas de interesse e a remoção dos interferentes, assim, classes específicas de compostos de interesse são selecionadas, por isso, é extremamente difícil adotar uma metodologia universal. Dessa forma, os procedimentos empregados nas extrações em micro-organismos envolvem diversas etapas como extrações sequenciais com diferentes solventes, centrifugação, evaporação, filtração e até mesmo etapas utilizando cartuchos de extração em fase sólida. ${ }^{26,45,63-66}$ Para tanto, procedimentos de extração mais complexos são empregados, envolvendo principalmente etapas de extração líquido-líquido e extração em fase sólida (SPE, do inglês solid phase extraction). Estudos recentes comprovaram a eficácia na utilização da mistura ternária $\left(\mathrm{H}_{2} \mathrm{O}: \mathrm{MeOH}: \mathrm{CH}_{3} \mathrm{CN}\right)$ na extração de metabólitos de Pseudomonas syringae com o objetivo de avaliar sua resposta a adaptação de ambientes em diferentes temperaturas. ${ }^{61,62}$ 
Ao se tratar de metabólitos voláteis, a principal técnica utilizada nos estudos metabolômicos é a microextração em fase sólida (SPME, do inglês solid phase microextraction). Uma grande vantagem da utilização da técnica de SPME nesses estudos é a possibilidade da realização da análise in vivo ${ }^{68}$ Estudos recentes demonstram o poder da ferramenta de SPME ao extrair um grande número de compostos orgânicos voláteis. ${ }^{69}$ Esses estudos têm sido aplicados nos mais diferentes gêneros de micro-organismos, tais como Lactobacillus buchneri,${ }^{70}$ E. coli, ${ }^{71}$ Clostridium difficile,${ }^{72}$ S. cerevisae,${ }^{73}$ dentre outros.

Utilizando a técnica de SPME, Mousavi e colaboradores avaliaram o perfil metabólico de E. coli, incluindo 500 metabólitos identificados por LC-MS e 789 componentes detectados por GC $\times$ GC-TOF-MS. Dos metabólitos detectados pela plataforma de GC $\times$ GC-TOF-MS, 125 foram identificados como metabólitos desregulados, revelando mudanças no metaboloma provocadas pela atividade antibacteriana do óleo de cravo e, em particular, o seu principal constituinte, o eugenol. A avaliação dos metabólitos voláteis por SPME foi extremamente eficaz e demonstrou que a variação nos metabólitos frente ao tratamento empregado foi facilmente detectada. ${ }^{71}$

A padronização de protocolos analíticos e métodos de extração é um dos tópicos mais discutidos entre os membros da comunidade interessada nos estudos metabolômicos. Tais discussões convergem quanto a inexistência de uma técnica analítica ou método de extração universal para determinação abrangente dos metabólitos de um sistema biológico. Dessa forma, é importante compreender que a combinação de diferentes técnicas de análise e extração poderão ampliar o número de metabólitos extraídos, mas a padronização desses métodos se faz necessária, a fim de obter perfis de metabólitos intracelulares globais e mais precisos e, consequentemente, obter uma interpretação biológica mais precisa dos dados metabolômicos. ${ }^{15,25}$ Além disso, a utilização de técnicas miniaturizadas também tem sido um grande atrativo no preparo de amostras em análises metabolômicas e o crescente emprego dessas ferramentas também proporcionou a aplicação dessas em micro-organismos. ${ }^{74,75}$ Outros tipos de extração e procedimentos mais detalhados podem ser encontrados em artigos de revisão que tratam especificamente dessa etapa. ${ }^{25,76}$

\section{Ferramentas Analíticas Aplicadas à Análises metabolômicas}

Apesar dos grandes avanços em instrumentação analítica ao longo dos últimos anos, um desafio ainda enfrentado pela metabolômica microbiana é a cobertura de todos os compostos por uma única técnica analítica. $^{22} \mathrm{O}$ perfil global de metabólitos requer técnicas analíticas capazes de medir uma variedade de classes químicas de moléculas em amostras biológicas, potencialmente existentes em uma ampla gama de concentrações. ${ }^{5}$

Por conseguinte, a análise eficaz é atingida através da combinação de diferentes ferramentas analíticas para obter a maior informação possível sobre o perfil de metabólitos de uma população de células ou organismo. ${ }^{22}$ Dentro de metabolômica de micro-organismos as principais técnicas analíticas empregadas são a NMR, GC-MS (do inglês, Gas Chromatography-Mass Spectrometry) e LC-MS (do inglês, Liquid Chromatography-Mass Spectrometry), sendo as principais aplicações dessas técnicas destacadas a seguir.

\section{$G C-M S$}

A GC-MS é uma técnica de análise muito utilizada em estudos metabolômicos, em que várias centenas de compostos podem ser analisados simultaneamente, incluindo ácidos orgânicos, aminoácidos, açúcares, álcoois, aminas aromáticas, ácidos graxos, dentre outros, onde em alguns casos a derivatização é necessária. ${ }^{5,15}$ Uma grande vantagem para a aplicação em estudos metabolômicos é a disponibilidade de bibliotecas espectrais em GC-MS. Essas bibliotecas oferecem ótimas possibilidades para a identificação de biomarcadores desconhecidos. ${ }^{77}$ Além disso, a análise de compostos voláteis por headspace vem sendo bastante empregada para acessar a porção volátil do metaboloma, possibilitando até mesmo estudos in vivo. ${ }^{68,78}$

Contudo, o grande limitante na análise metabolômica utilizando GC-MS é a volatilidade dos compostos, pois grande parte dos metabólitos que compõem o metaboloma requerem derivatização para que se tornem voláteis nas temperaturas de trabalho do cromatógrafo a gás. ${ }^{15}$ As variações nos experimentos de derivatização e formação de compostos indesejados são duas questões fundamentais que podem influenciar diretamente a análise. Dessa forma, métodos de derivatização reprodutíveis e eficientes são elementos essenciais para análises utilizando GC-MS. ${ }^{77}$

As reações de derivatização permitiram análises de ácidos graxos e outros lipídios em micro-organismos. ${ }^{79}$ Análises de perfis de fosfolípidios de Penicillium chrysogenum foram empregadas para avaliar essa variação em diferentes condições de cultivo do micro-organismo. ${ }^{80} \mathrm{~A}$ GC-MS também foi empregada na análise de ácidos graxos submetidos à derivatização ${ }^{81,82}$ tanto para avaliações de perfil lipídico $^{82,83}$ quanto para identificações específicas. ${ }^{84-87}$

$\mathrm{O}$ estudo da produção metabólica em diferentes meios de cultura foi realizado para os micro-organismos Escherichia coli e Saccharomyces cerevisiae onde GC-TOF-MS (do inglês, Gas Chromatography - Time of Flight Mass Spectrometry) foi utilizada na identificação e quantificação dos metabólitos intracelulares. ${ }^{35}$ Além da utilização da abordagem alvo-orientada ${ }^{38} \mathrm{em}$ GC-MS, as abordagens globais também têm sido empregadas em análises de diversos micro-organismos. . $^{434,46,52} \mathrm{Um}$ estudo realizado com as cepas de Candida albicans e Staphylococcus aureus buscou avaliar o perfil global dos metabólitos intracelulares e extracelulares dos micro-organismos utilizando para tal análise um GC-Orbitrap-MS. ${ }^{52}$ Tanto o GC-TOF-MS quanto o GC-Orbitrap-MS são sistemas que possuem analisadores de massas de alta resolução, permitindo assim a obtenção de massa exata e possibilidade de identificação ainda mais confiável para esses metabólitos, o que vem a ser um grande atrativo.

Como já explicitado, a utilização de uma única plataforma para investigação metabolômica acaba limitando o número de metabólitos alcançados e a distinção entre classes químicas. Por isso, tem se tornado cada vez mais comum observar estudos nos quais diferentes abordagens são empregadas, principalmente técnicas cromatográficas como GCMS e LC-MS ${ }^{45,88,89}$ A avaliação do exometaboloma de Saccharomyces cerevisiae utilizando ambas as plataformas permitiram uma investigação ampla do perfil metabólico no processo fermentativo da levedura correlacionando os metabólitos identificados com as diferentes vias bioquímicas das células do micro-organismo ${ }^{88}$ observando dessa forma, mudanças metabólicas e fisiológicas em resposta à hipóxia.

Diante da alta complexidade da amostra e do grande número de metabólitos presentes em micro-organismos, a cromatografia gasosa bidimensional abrangente $(\mathrm{GC} \times \mathrm{GC})$ vem sendo utilizada como alternativa à GC-MS tradicional. As vantagens da abordagem por $\mathrm{GC} \times \mathrm{GC}$ são as superiores sensibilidade analítica e capacidade de pico. ${ }^{90,91}$ Estudos avaliando o metaboloma volátil de Klebsiella pneumoniae $^{69,92}$ e outros micro-organismos ${ }^{68,70,93}$ têm expandido horizontes na exploração de compostos voláteis provenientes de micro-organismos antes não observados nas técnicas unidimensionais. Diversos estudos envolvendo a GC×GC têm sido empregados tanto na análise alvo quanto não alvo. Na Tabela 1 é possível encontrar diversas aplicações utilizando essa técnica, principalmente quando associada à SPME.

\section{$L C-M S$}

A cromatografia líquida acoplada à espectrometria de massas (LC-MS) tornou-se uma importante ferramenta analítica em 
metabolômica, e também foi aplicada em estudos sobre muitos sistemas biológicos. ${ }^{22,94}$ A LC-MS é sem dúvida a plataforma mais adequada para a análise de compostos polares e não polares pouco voláteis, nos quais não é viável uma reação de derivatização. ${ }^{5}$ É uma técnica analítica que apresenta alta robustez, sensibilidade e seletividade. ${ }^{15}$

Diversas opções são disponíveis para fontes de ionização e analisadores de massas em sistemas LC-MS possibilitando a realização tanto de análises alvo como abordagens globais, o que faz da LC-MS um grande atrativo para os estudos microbiológicos. A LC-MS permite portanto, a possibilidade de realizar tanto análises qualitativas quanto análises quantitativas, fornecendo informações estruturais a partir de dados MS/MS, e quantificações simultaneamente sem a necessidade de altas resoluções cromatográficas. Nas duas últimas décadas, várias plataformas LC-MS foram utilizadas com sucesso na análise metabolômica, sendo aplicadas à diversas matrizes microbiológicas. ${ }^{95,96} \mathrm{O}$ modo de monitoramento de reações selecionadas (SRM, do inglês Selected Reaction Monitoring) em LC-MS/MS usando um analisador triplo quadrupolo também tem sido aplicada principalmente na identificação e quantificação de lipídios e outros metabólitos. ${ }^{84,97,98}$

As aplicações para LC-MS dentro do contexto da análise metabolômica de micro-organismos são bastante amplas, e a grande quantidade de informação gerada acaba tornando o uso de ferramentas de análises de dados essenciais nesses estudos. ${ }^{36,64,99,100}$ Uma abordagem recente que também tem ganhado espaço dentro das análises metabolômicas é a associação da espectrometria de massas com a técnica de mobilidade iônica UHPLC-TWIM-MS (do inglês, Ultra High Performance Liquid Chromatography combined with Traveling Wave Ion Mobility Mass Spectrometry). Essa abordagem tem sido empregada com sucesso para aumentar a capacidade de sinais e possibilitar a separação de espécies isoméricas..$^{53,101,102}$ As produções de metabólitos e lipídios foram monitoradas em linhagens intactas e geneticamente modificadas de $C$. reinhardtii, com comprometimento da via de amido. Os lipídios, tais como triacilgliceróis (TAG) e diacilgliceril-N, N, N-trimetil-homosserina (DGTS), foram avaliados ao longo do tempo sob diferentes condições de luz. Mais de 200 metabólitos, tais como arginina, cisteína, serina, palmitato, clorofila a, clorofila b, etc., foram detectados, ${ }^{101}$ demonstrando que a técnica empregada foi extremamente eficiente na identificação de metabólitos de diferentes características químicas.

Uma aplicação da LC-MS recente e bastante interessante foi a utilização de metabólitos secundários de Streptomyces (8 espécies, 14 cepas) para classificação quimiotaxonômica. Assim, esse estudo demonstrou que esse tipo de classificação baseada em metabólitos é uma ferramenta eficaz para distinguir Streptomyces spp. e para determinar os metabólitos específicos da espécie. ${ }^{47}$ Além das análises exploratórias, estudos específicos para a descoberta de novas classes de compostos, como antibióticos produzidos a partir de micro-organismos também têm sido desenvolvidos, sendo que a LC-MS é amplamente empregada na caracterização desses novos compostos. ${ }^{103-105}$ É evidente que a LC-MS é a plataforma mais empregada em estudos metabolômicos em geral, contudo, devido à alta complexidade dessas amostras a cromatografia liquida bidimensional (LC×LC) também têm ganhado destaque nos estudos metabolômicos. Apesar de ainda ser pouco popular, a LC $\times \mathrm{LC}$ compreende vantagens similares à $\mathrm{GC} \times \mathrm{GC}$ e possibilita ampliar ainda mais a quantidade de metabólitos investigados simultaneamente, buscando conhecer de forma detalhada esses sistemas e suas possíveis variações.

\section{Imageamento por $M S$}

Dentre outras técnicas baseadas em MS, a ionização e dessorção à laser assistida por matriz (MALDI, do inglês matrix-assisted laser desorption/ionization) também tem sido usada nos estudos metabólicos de diferentes cepas de micro-organismos. ${ }^{60}$ Além das diversas aplicações em estudos metabólicos gerais, ${ }^{41,87,106,107}$ vale destacar a utilização de MALDI na análise de impressões digitais lipídicas de vírus intactos ${ }^{108}$ e também em aplicações de imageamento. ${ }^{20,109} \mathrm{O}$ imageamento por espectrometria de massas (MSI, do inglês Mass Spectrometry Imaging) permite o estudo da distribuição espacial de pequenas moléculas em amostras biológicas. ${ }^{110}$ Essa metodologia foi introduzida em 1997 por Caprioli e colaboradores, e aplicada principalmente na superfície de tecidos biológicos intactos para criar imagens 2D com base na distribuição espacial de peptídeos e proteínas. ${ }^{111}$

Essa técnica tem sido expandida e utilizada no estudo espacial de metabólitos e lipídios em diferentes matrizes biológicas, análise de produtos naturais microbianos, ${ }^{113}$ interações microbianas entre culturas mistas ${ }^{114}$ e caracterização metabólica de micro-organismos. ${ }^{115,116} \mathrm{~A}$ técnica de imageamento por MALDI-TOF por exemplo, foi utilizada a fim de caracterizar a distribuição espacial de metabólitos produzidos por cianobactérias de diferentes complexidades. Uma série de metabólitos produzidos pelas cianobactérias Lyngbya majuscula, Oscilatoria nigro-viridis, Lyngbya bouillonii e uma espécie Phormidium, mesmo quando estavam presentes como misturas, foram identificados. Além da jamaicamida $\mathrm{B}$, um produto natural conhecido da cianobactéria Lyngbya majuscula JHB, um grande número de íons desconhecidos localizados nas diferentes cianobactérias foi detectado, possibilitando a exploração de novos metabólitos nos organismos investigados.

Em uma abordagem recente sobre o perfil metabólico de diferentes cepas de Lysobacter, relatou-se a aplicação de MALDI-MSI em complemento às análises do genoma in silico frente ao estudo das interações entre Lysobacter e Rhizoctonia solani, sendo esse último uma espécie de patógeno fúngico economicamente importante. Através da técnica de imageamento, foi possível identificar os compostos bioativos bem como os padrões de distribuição espacial desses compostos na interação entre os dois micro-organismos. ${ }^{96}$ Dessa forma, é possível perceber que a técnica de MALDI-MSI tem sido empregada na metabolômica microbiana, e apesar de algumas limitações referentes às condições experimentais imposta pela técnica, essa ainda tem demonstrado excelentes resultados principalmente na identificação de micro-organismos e também em promover diversidade química.

$\mathrm{O}$ avanço das técnicas de imageamento por espectrometria de massas de alta resolução também viabilizou a possibilidade de informações detalhadas e elementares em sistemas microbianos possibilitando o monitoramento não invasivo e in situ dessas comunidades. ${ }^{117,118}$ As técnicas de ionização ambiente em imageamento por espectrometria de massas têm sido uma escolha popular para apresentar a distribuição espacial de moléculas in situ devido à pouca ou nenhuma preparação de amostra e sem interferência de matriz, onde a ionização de dessorção por electrospray (DESI, do inglês Desorption Electrospray Ionization) é o sistema mais utilizado. ${ }^{19,120}$ Vale destacar o desenvolvimento e adaptação de outras fontes de ionização que permitam análises in situ como a ionização por eletrospray com ablação a laser (LAESI, do inglês Laser Ablation Electrospray Ionization), análise direta em tempo real (DART, do inglês Direct Analysis in Real Time), além dos grandes avanços tecnológicos que permitiram a realização de imageamento por MS, de modo que fosse possível visualizar metabólitos dentro de resoluções espaciais $<1 \mu \mathrm{m}$ em pressões atmosféricas e com alta precisão e resolução em massa. ${ }^{22}$

Também é importante ressaltar que outras técnicas emergentes baseadas em espectrometria de massas ainda pouco difundidas, tais como espectrometria de massas de ionização evaporativa rápida (REIMS, do inglês Rapid Evaporative Ionization Mass Spectrometry) e espectrometria de massas por pulverização em papel (PS-MS, do 


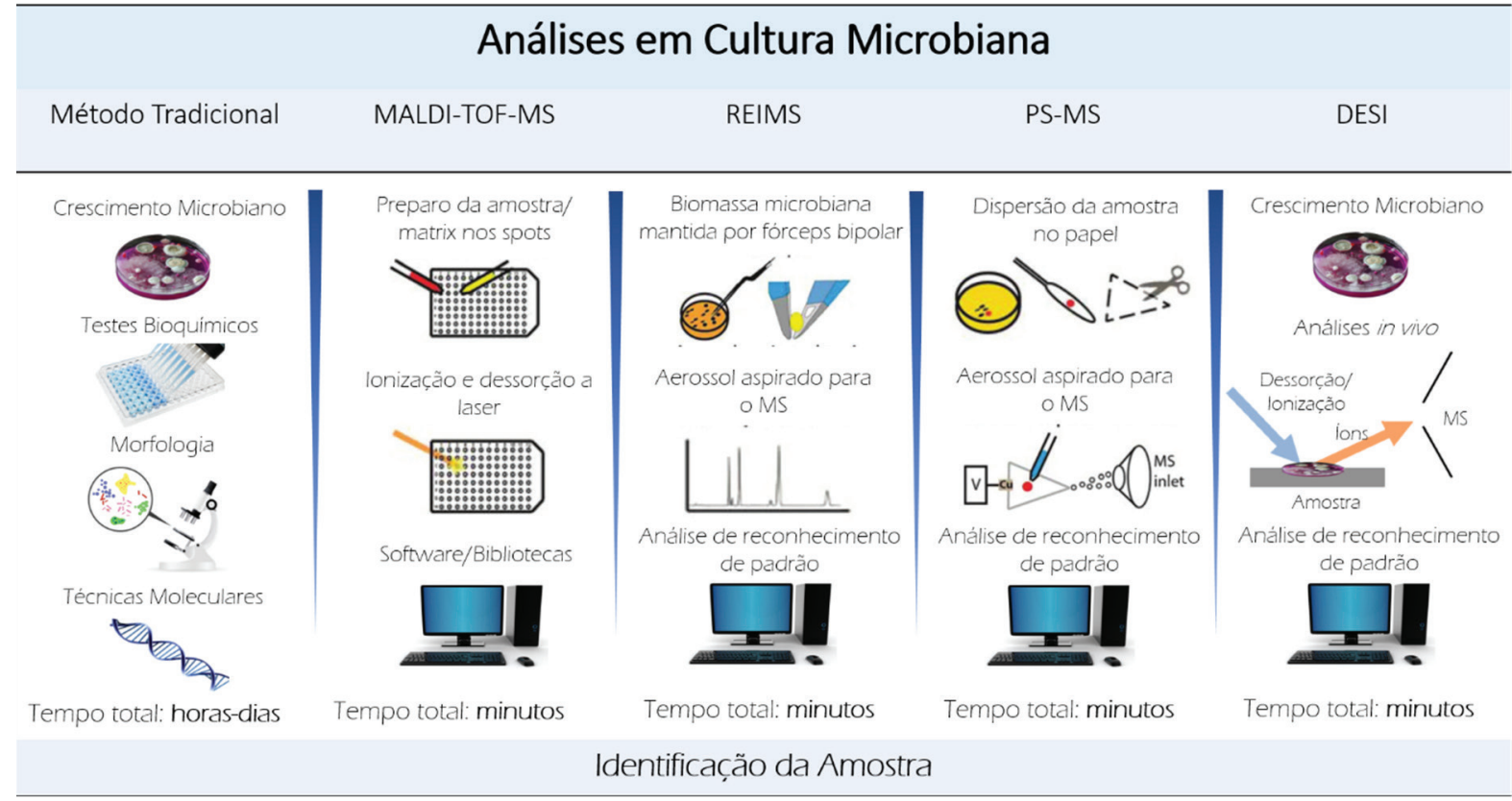

Figura 2. Fluxos de trabalho para identificação microbiana. Método tradicional; Ionização e dessorção a laser assistido por matriz. (MALDI) espectrometria de massas (MS) por tempo de voo (TOF); Espectrometria de massas com ionização evaporativa rápida (REIMS); Espectrometria de massas por pulverização em papel (PS-MS); Ionização de Dessorção por Electrospray (DESI). Extraído de Luzzatto-Knaan et al. 2015. ${ }^{121}$ Copyright 2015, com autorização da revista Analyst

inglês Paper Spray-Mass Spectrometry) têm demonstrado eficiência nos estudos metabolômicos, a fim de facilitar o preparo de amostra e minimizar os tempos de análise, como pode ser visto na Figura 2. Essas técnicas têm sido aplicadas tanto na identificação de micro-organismos quanto nos estudos metabólicos individuais ou de interação microbiana. ${ }^{121}$

O futuro da metabolômica microbiana certamente está relacionado com os avanços em técnicas analíticas que permitam a utilização de amostras de biomassa muito pequenas. Nesse sentido, a espectrometria de massas parece ser a tecnologia com o melhor potencial para alcançar esses objetivos. ${ }^{22}$ Mediante os trabalhos avaliados, é possível observar que a utilização de múltiplas plataformas é extremamente interessante nos estudos metabolômicos, possibilitando uma ampla faixa de investigação, levando a resultados confiáveis e com uma grande quantidade de informação.

\section{Processamento e análise de dados}

Os dados gerados a partir das análises metabolômicas são abundantes e de alta complexidade e, por isso, ferramentas adequadas ao tratamento de dados devem ser empregadas a fim de evitar erros de interpretação dos resultados e manter a integridade das variações biológicas inspecionadas. ${ }^{15}$ Assim, um dos maiores desafios da metabolômica envolve o pré-processamento e a análise de dados, sendo necessárias amplas opções de softwares e estratégias para transformar dados brutos em resultados biológicos úteis. ${ }^{122}$ As ferramentas necessárias nesse processamento incluem estratégias para processar arquivos tanto de GC-MS e LC-MS quanto de NMR, onde uma série de ferramentas de análise estatística, bancos de dados de metabólitos e, finalmente, softwares de bioinformática são utilizados. ${ }^{15}$

\section{Pré-processamento}

O pré-processamento de dados é um passo intermediário entre a aquisição direta e a análise dos dados. ${ }^{5}$ A maioria dos softwares de pré-processamento compartilham as funções gerais de deconvolução de sinais analíticos, filtragem de ruído, detecção e alinhamento de picos cromatográficos, correção da linha de base e preenchimento de lacunas (gap filling), embora as capacidades, vantagens e limitações variem drasticamente dentre a grande possibilidade de softwares atualmente disponível. ${ }^{15,122,123}$ As etapas gerais de processamento podem ser resumidas na Figura 3, onde as principais etapas são descritas, podendo haver variações mediante à aplicação empregada e ao objetivo da análise.

O principal objetivo da filtragem de ruído é separar o sinal

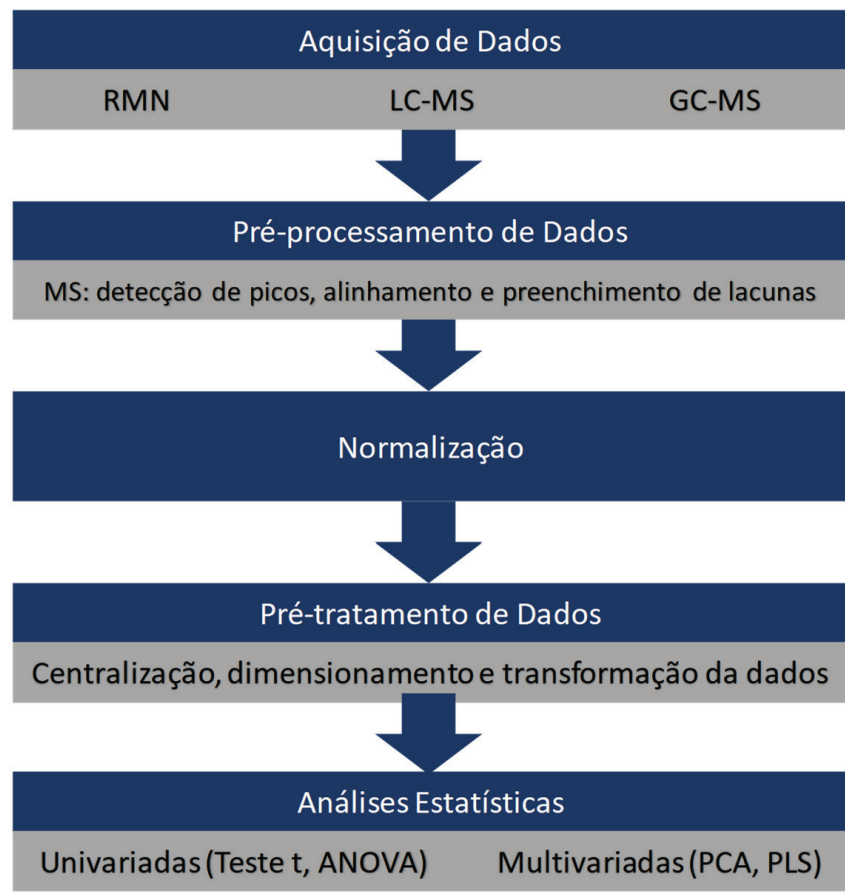

Figura 3. Etapas de processamento geral da análise de dados metabolômicos, desde a aquisição de dados até a análise estatística. Adaptado de A. Sussulini, ed., Metabolomics: From Fundamentals to Clinical Applications, Springer International Publishing, Cham, 2017. ${ }^{124}$ Copyright 2015, com autorização da Springer 
proveniente de um composto na amostra biológica de um sinal de fundo proveniente de interferência química ou instrumental, facilitando a etapa de detecção de picos ${ }^{125,126} \mathrm{~A}$ detecção de pico/deconvolução compreende a identificação da forma correta de um sinal que potencialmente é de um composto, ou seja, detecta cada íon medido em uma amostra e atribui a um sinal cromatográfico (par $m / z-R T$ (do inglês, retention time). ${ }^{123,124} \mathrm{O}$ objetivo da detecção e deconvolução de pico é identificar e quantificar os sinais correspondentes às moléculas nas amostras; assim, um método de detecção de pico eficiente deve identificar os sinais verdadeiros e evitar falsos positivos. Além disso, a detecção de picos e a deconvolução reduzem a complexidade dos dados e tornam a posterior análise viável. ${ }^{126}$

Outra etapa de extrema importância no pré-processamento de dados cromatográficos é o alinhamento dos picos entre as amostras. De forma resumida, o algoritmo de alinhamento visa corrigir oscilações aleatórias de tempo de retenção de um mesmo pico entre diferentes amostras. ${ }^{124}$ Já o algoritmo de preenchimento de lacunas é utilizado para recuperar os sinais que podem ter sido eliminados nas etapas anteriores de pré-processamento a partir dos dados brutos. ${ }^{126}$

A normalização é o processo que visa corrigir a variação sistemática e escalar os dados para que diferentes amostras em um estudo possam ser comparadas entre si, sendo assim, é aplicado dividindo cada linha de tabela de dados por um fator de normalização. ${ }^{4}$ Duas estratégias principais são comumente usadas para remover o viés sistemático indesejado nas medidas. A primeira é o uso de padrões internos, no qual a seleção desses padrões pode ser baseada em regiões específicas de RT ou $m / z$, mas RT e $m / z$, contudo, nem sempre são descritivos de todas as propriedades matriciais e químicas levando a obscurecer a variação de dados. ${ }^{126}$ Outra estratégia sofisticada para a normalização é o uso de amostras de controle de qualidade (QC, do inglês Quality Control) em cada procedimento de aquisição de dados a fim de visualizar a variabilidade global de um sistema de medição. As amostras de QC referem-se à mistura de volumes iguais de todas as amostras envolvidas no estudo (todos os grupos avaliados). ${ }^{15}$ Assim, as amostras estudadas são comparadas com QCs para avaliar sua reprodutibilidade, desempenho e estabilidade instrumental., ${ }^{4}$

As funções descritas anteriormente na etapa de pré-processamento são desempenhadas automaticamente com o auxílio de diferentes softwares e plataformas online e, por isso, um grande volume de novas ferramentas vem sendo desenvolvido nos últimos anos. ${ }^{5,125}$ Contudo, é importante salientar que a etapa de pré-processamento de dados automático e eficaz continua a ser uma tarefa difícil, especialmente para a detecção, alinhamento e deconvolução de picos de baixa intensidade. ${ }^{4}$ Algumas das principais plataformas/softwares empregadas no pré-processamento de dados metabolômicos foram compiladas na Tabela 2, sendo em seguida apresentadas algumas aplicações para micro-organismos quando existentes. A maioria dessas ferramentas apresentadas está disponível gratuitamente e podem ser empregadas para dados de LC-MS e GC-MS.

Outras listas de softwares disponíveis podem ser encontradas em artigos de revisão focados em pré-processamento e análise de dados. ${ }^{4,125,126}$ Além disso, muitos fabricantes de instrumentos também oferecem seu próprio software, por exemplo, MarkerLynx (Waters), MassProfiler (Agilent), MarkerView (SCIEX) e SIEVE (Thermo Fisher Scientific).

A plataforma MultAlign foi utilizada no pré-processamento de dados de LC-MS para análises metabolômicas de Yarrowia lipolytica antes da etapa de análise de dados. ${ }^{42}$ Em alguns casos, as etapas de pré-processamento são integradas ao software do equipamento no qual a análise foi realizada, não necessitando de outras plataformas externas. ${ }^{107,131}$ Além disso, a plataforma XCMS-online, que é uma ferramenta bastante difundida nos estudos metabolômicos, foi utilizada no tratamento de dados para Pseudomonas syringae, ${ }^{61}$ Streptomyces
Tabela 2. Plataformas e softwares de pré-processamento mais utilizados em metabolômica

\begin{tabular}{lc}
\hline Nome & Website \\
\hline XCMS & https://xcmsonline.scripps.edu/ \\
MZmine & http://sourceforge.net/projects/mzmine/ \\
OpenMS & http://open-ms.sourceforge.net/ \\
MetAlign & http://www.metalign.nl \\
MetSign ${ }^{127}$ & http://metaopen.sourceforge.net/metsign.html \\
MSFACTs $^{128}$ & http://bioinfo.noble.org/download/ \\
Metabolite Detector ${ }^{129}$ & http://metabolitedetector.tu-bs.de/ \\
MET-IDEA ${ }^{130}$ & http://bioinfo.noble.org/download/ \\
SpectConnect & http://spectconnect.mit.edu \\
MultAlign & http://multalin.toulouse.inra.fr/multalin/
\end{tabular}

sp. ${ }^{36}$ Candida albicans and Staphylococcus, ${ }^{52}$ e no tratamento de dados referente a um estudo de co-culturas de bactérias e fungos. ${ }^{60}$

\section{Análise de dados}

As técnicas de análise estatística univariada e multivariada são usadas para extrair informações relevantes sobre o problema estudado. Além disso, ferramentas estatísticas como o teste $t$, análise de variância (ANOVA), ${ }^{66}$ análise de componentes principais (PCA, do inglês Principal Component Analysis) ou a análise discriminante por mínimos quadrados parciais (PLS-DA, do inglês, Partial Least Squares-Discriminant Analysis) são geralmente componentes essenciais em estudos de metabolômica. A adequação de um teste estatístico para melhor detectar a expressão diferencial nos estudos de interesse é determinada pela distribuição de dados e problema biológico a ser resolvido ou investigado. ${ }^{123}$ Antes da análise de dados propriamente dita, em alguns casos são utilizadas etapas de pré-tratamento, onde os dados são submetidos a diferentes ferramentas estatísticas como centralização, dimensionamento e transformação de dados que são utilizadas para minimizar os erros experimentais, maximizando as variações biológicas relevantes. ${ }^{124}$ A quantidade de ferramentas estatísticas que tem sido aplicada em análises metabolômicas é bastante vasta, por isso esta revisão foi direcionada às principais ferramentas aplicadas nas análises de micro-organismos, concentrando-se nas ferramentas multivariadas.

Nas análises multivariadas, a classificação e discriminação de entidades ou metabólitos responsáveis por diferenciar os grupos de amostras são realizadas através da avaliação do conjunto da matriz de dados extraídos na etapa de pré-processamento., ${ }^{4,15}$ Os métodos não supervisionados podem revelar os fatores mais importantes de variabilidade que caracterizam o conjunto de dados, que normalmente são distintos do fator especificamente investigado. Geralmente são usados para explorar a estrutura geral de um conjunto de dados, encontrar tendências e agrupamentos dentro do conjunto, contribuindo com uma visão imparcial dos dados. ${ }^{4,123}$ Vários métodos não supervisionados têm sido aplicados, dentre os quais a PCA e a análise de agrupamento hierárquico (HCA, do inglês Hierarchical Cluster Analysis) são os exemplos mais utilizados na metabolômica. ${ }^{4}$ Além disso, a análise de componentes principais multimodo (MPCA, do inglês Multilinear Principal Component Analysis) também tem sido utilizada nos estudos metabolômicos de micro-organismos. ${ }^{68,71,132}$

Já os métodos supervisionados utilizam estruturas de dados conhecidas para treinar padrões com o intuito de prever a classe de novos dados. Esses métodos podem ser classificados como métodos lineares, como PLS-DA, análise discriminante linear (LDA, do inglês Linear Discriminant Analysis), projeções ortogonais para estruturas 
latentes (OPLS-DA) e métodos não-lineares. ${ }^{4} \mathrm{O}$ método supervisionado mais utilizado para classificação em quimiometria é a PLS-DA, que é uma combinação de regressão multivariada por PLS com a análise discriminante. ${ }^{133} \mathrm{~A}$ vantagem da PLS-DA é a sua capacidade de lidar com dados altamente colineares. Além disso, a PLS-DA pode fornecer informações excelentes sobre a causa da discriminação, verificando o comportamento das variáveis, sendo também uma ferramenta útil na descoberta de biomarcadores. ${ }^{5}$ Uma interessante modificação de PLS-DA é a OPLS-DA (do inglês Orthogonal Partial Least Squares) na qual as variações sistemáticas na matriz de dados $X$ podem ser divididas em duas partes através da técnica de correção de sinal ortogonal (OSC, do inglês Orthogonal Signal Correction): uma parte exibe os padrões multivariados correlacionados à resposta experimental, enquanto os padrões ortogonais são representados na segunda parte. A distinção entre as diferentes fontes de variação nos dados, por exemplo correlacionada versus ortogonal, impõe uma importante vantagem da OPLS-DA na visualização e interpretação dos dados em relação à PLS-DA, e tem sido amplamente aplicada na modelagem e descoberta de importantes compostos na análise metabolômica de micro-organismos. . $6,37,44,64,67^{-}$

A PCA foi empregada para avaliar a diferença no perfil lipídico de diferentes espécies de Cryptococcus $s p$, nos quais os principais compostos responsáveis pela diferenciação foram identificados. ${ }^{84}$ Tanto o pré-processamento quanto a aplicação de ferramentas multivariadas foram utilizadas para a classificação de amostras de Bacillus $s p$. e Brevibacillus sp. utilizando o perfil lipídico. ${ }^{41}$ Outras aplicações de $\mathrm{PCA}^{42,82,134}$ e $\mathrm{HCA}^{80}$ para a análise exploratória e diferenciação de micro-organismos são encontradas na literatura utilizando o perfil lipídico como diferenciador das cepas. A PLS-DA também tem sido aplicada como método para discriminação de amostras e identificação de compostos diferenciadores na classificação de micro-organismos ${ }^{66,98}$ muitas vezes empregado juntamente com a PCA..$^{38,135,136}$ Dessa forma, resultados mais confiáveis com relação a discriminação e classificação de amostras são obtidos pela associação das duas estratégias.

Mediante a alta complexidade dos dados metabolômicos, ferramentas como heatmaps têm sido empregadas a fim de facilitar a visualização dos metabólitos identificados e condições avaliadas. ${ }^{49}$ A visualização dos dados se torna ainda mais explicativa quando as ferramentas de PCA e heatmaps são empregadas em conjunto, sendo essas ferramentas extremamente úteis nesse contexto. ${ }^{35,49,63,100,137}$ Além disso, PCA e HCA também são utilizadas em conjunto para facilitar na compreensão dos problemas biológicos investigados. . $^{35,46,92}$

A ferramenta de PLS-DA foi utilizada para a avaliação das variações metabólicas de Pseudomonas syringae frente às mudanças de temperatura. Algumas amostras representativas das classes investigadas foram utilizadas para a elaboração do modelo estatístico que utilizou tanto dados de NMR quanto MS, fornecendo resultados satisfatórios em ambos os casos. ${ }^{61}$ Além disso, a ferramenta também foi empregada juntamente com HCA na análise de Streptomyces $s p$. como uma ferramenta de classificação quimiotaxonômica baseada em metabolômica. ${ }^{47}$ A MCR-ALS (do inglês, Multivariate Curve Resolution with Alternating Least Squares) é um método amplamente utilizado na resolução de curvas, essa ferramenta foi empregada com o objetivo de resolver diretamente o número máximo de perfis de eluição individuais e perfis espectrais de massa pura de todos os metabólitos possíveis extraídos das amostras de leveduras avaliando também o efeito da exposição ao $\mathrm{Cu}$ (II) sobre elas. ${ }^{29}$

De forma a facilitar e integrar as etapas de processamento de dados, algumas plataformas agrupam as etapas de pré-processamento com a análise estatística, como é o caso da MetaboNexus, MetaboAnalyst e MetaComp, ${ }^{138}$ que permitem ao usuário realizar PCA, PLS-DA, e outras análises multivariadas e univariadas. Além disso, elas integram a possibilidade de reportes gráficos, como gráficos de scores, gráficos de diagnóstico e heatmaps, enquanto a função de busca de metabólitos usa três repositórios principais de metabólitos, HMDB, MassBank e METLIN ${ }^{123}$ facilitando assim, a etapa de tratamento de dados.

\section{Identificação dos metabólitos}

A elucidação estrutural é outro componente essencial das análises metabolômicas e é um processo desafiador e demorado, especialmente na metabolômica microbiana. ${ }^{121}$ Isso ocorre porque os micro-organismos podem produzir uma gama muito diversificada de metabólitos em diferentes condições, que podem não ser comumente reconhecidos em bibliotecas padrão. ${ }^{5}$

Embora seja possível realizar a elucidação estrutural de um único metabólito utilizando métodos baseados em NMR ou MS, essa tarefa se torna extremamente inviável para os estudos metabolômicos, em que, centenas a milhares de compostos são detectados simultaneamente. Dessa forma, a identificação é baseada em características de correspondência dos espectros da amostra em relação a uma base de dados de referência. ${ }^{124}$ Assim, em complemento aos dados de LC-MS e GC-MS comuns, informações adicionais são alcançadas a partir de espectros de massa de ordem superior, como MS ${ }^{\mathrm{n}}$. As fragmentações sofridas pelas espécies de interesse fornecem uma impressão digital da estrutura molecular que podem ser comparadas com as bibliotecas de espectros disponíveis. ${ }^{139}$

Apesar das limitações, mediante o crescente interesse nos estudos metabolômicos de micro-organismos e, consequentemente, a geração de informações, uma série de bases de dados microbianas baseada em dados de NMR e MS têm surgido, acelerando assim o processo de identificação dos metabólitos. Paralelamente, os pesquisadores também podem recorrer a bancos de dados de metabolômica geral que também podem fornecer informações úteis. ${ }^{5}$ Os bancos de dados HMDB e METLIN foram empregados na identificação de metabólitos provenientes da bactéria Pseudomonas syringae a fim de investigar os metabólitos relevantes frente às variações de temperatura para a espécie. ${ }^{61}$ Contudo, apesar de se tratar de um banco de dados para o metaboloma humano, o HMDB tem sido utilizado também na elucidação estrutural de compostos provenientes de micro-organismos. ${ }^{26,37}$ Além disso, bibliotecas como Fiehn ${ }^{140}$ e NIST $^{69}$ também são amplamente empregadas..$^{35}$

Embora as bibliotecas espectrais de massas estejam crescendo, a quantidade de moléculas identificadas ainda é relativamente pequena em comparação ao número de compostos que poderiam estar presentes em amostras típicas, principalmente quando não há dados de referência disponíveis, como é o caso de diversos micro-organismos. Assim, as ferramentas computacionais aliadas à MS buscam sanar esses problemas com o desenvolvimento de plataformas altamente eficazes. Essas plataformas são capazes de propor identificações de compostos desconhecidos, utilizando a consulta de diferentes bases de dados e combinação da informação extraída para o processo de identificação. Plataformas como MetFrag e MetFusion têm permitido o processamento de centenas de espectros de fragmentação de MS em poucos minutos e a adição de diferentes tipos de informações mostrou melhorar as taxas de identificação de $6 \%$ até $70 \%$, dependendo do conjunto de dados e fontes de informação utilizadas. ${ }^{139}$

As ferramentas de enriquecimento são estratégias que utilizam o conhecimento de base de dados e algoritmos estatísticos para executar o processo de identificação. A metodologia mais utilizada para realizar essa análise é denominada enriquecimento funcional ou análise de sobre-representação (ORA, do inglês Over-Representation Analysis). A ferramenta ORA é muito flexível e de fácil implementação, por isso tem sido aplicada em diversas plataformas metabolômicas e banco de dados. A análise se inicia com uma lista de metabólitos de interesse e 
testa se certos grupos de metabólitos aparecem mais frequentemente do que seria esperado por chance aleatória, sendo, para isso, aplicados testes estatísticos de comparação como teste t ou ANOVA e os metabólitos significantes são selecionados utilizando um limite ou critério específico. ${ }^{124,141}$ A fim de investigar a interferência do meio de cultura no metabolismo de Escherichia coli e Saccharomyces cerevisiae, uma outra ferramenta de enriquecimento (MSEA, do inglês Metabolite Set Enrichment Analysis) foi empregada utilizando a plataforma MetaboAnalyst. A MSEA utiliza diretamente o enriquecimento de grupos usando os dados de concentração completa sem pré-seleção de metabólitos significativos sendo possível identificar os compostos que diferem significativamente frente a uma variação, nesse caso o meio de cultura. ${ }^{35}$

Uma última ferramenta com desenvolvimento recente na metabolômica "Big Data" baseada em algoritmos matemáticos para organizar e visualizar dados MS é o molecular networking (MN). Várias publicações têm demonstrado o potencial do molecular networking em estudos de metabolômica microbiana com a capacidade de analisar conjuntos de dados em grande escala. ${ }^{30,50,64} \mathrm{O}$ funcionamento da ferramenta baseia-se no princípio de que estruturas moleculares análogas se comportam de maneira semelhante na fase gasosa, dando origem a padrões de fragmentação semelhantes na espectrometria de massas. $\mathrm{O}$ molecular networking é aplicado a partir de algumas etapas básicas: (1) coleta de dados MS/MS; (2) cálculo de similaridade de espectros usando um algoritmo especial para gerar uma rede molecular; (3) visualização da rede. Os dados são visualizados por similaridade química no qual um nó representa um espectro MS/MS de consenso marcado pela massa original dos íons precursores e a espessura da linha que os liga representa o escore de semelhança entre os espectros, criando grupos de famílias moleculares, quanto mais próximo o valor do escore de 1, maior a semelhança no espectro de MS/MS, sugerindo que os compostos possuem uma similaridade química. ${ }^{121}$ Na plataforma GNPS (gnps.ucsd.edu) é possível carregar os dados de MS/MS online e gerar o molecular networking, podendo ser visualizado na plataforma ou utilizando softwares como o Cytoscape. ${ }^{142}$

O MN foi aplicado na elucidação estrutural de diversos metabólitos provenientes de comunidades microbianas multiespécies sintéticas. Nesse caso, os metabólitos conhecidos das culturas individuais auxiliaram na descoberta de diferentes metabólitos presentes nas co-culturas. ${ }^{64}$ A plataforma também foi aplicada no estudo de Clostridium acetobutylicum apresentando uma estratégia de manipulação do metabolismo secundário de um organismo para melhorar traços relevantes para aplicações industriais. ${ }^{51}$ Devido à sua facilidade no tratamento de dados e emprego em diferentes áreas, o MN vem sendo amplamente utilizado nos estudos metabolômicos, especialmente nos estudos de micro-organismos, onde as plataformas e bancos de dados de metabólitos disponíveis ainda é escassa. ${ }^{30,50,143}$

Enquanto alguns metabolomas, como o metaboloma humano, têm sido amplamente caracterizados e disponibilizados para amplo acesso em bancos de dados, os bancos de dados de metaboloma microbiano têm se desenvolvido apenas para algumas espécies modelo. A falta de dados é um resultado direto da alta diversidade de organismos e espécies e o estudo dos metabolomas microbianos oferece muitas oportunidades para o desenvolvimento futuro. ${ }^{121}$

\section{DESAFIOS FUTUROS}

Muitos desafios ainda são encontrados no contexto da ciência metabolômica e, mais especificamente, na metabolômica microbiana. Dentre esses desafios, está a identificação simultânea de uma ampla gama de metabólitos intactos e a quantificação com precisão de cada molécula na amostra. ${ }^{144}$ Assim, a utilização de múltiplas plataformas analíticas é uma tendência emergente na metabolômica, e a integração dos dados obtidos por NMR e MS podem auxiliar na resolução dessas limitações. ${ }^{24}$ Diversos estudos apresentados nesta revisão demonstraram o uso de múltiplas plataformas nos estudos avançados de sistemas microbianos, contudo, esses estudos ainda não limitados, tanto em relação ao processamento de dados quanto a verdadeira compreensão global do sistema.

Em termos de preparo de amostras, também são encontradas algumas barreiras que precisam ser superadas, como por exemplo a falta de protocolos padrões em metabolômica microbiana para o quenching instantâneo da atividade metabólica, bem como para extração abrangente de metabólitos e análise dos metabólitos de interesse. Os procedimentos atuais são desenvolvidos para organismos específicos e são incapazes de prevenir a perda de metabólitos durante o preparo. Com relação aos métodos de extração utilizados, esses ainda são mais adequados para a análise de certas classes de metabólitos e precisam ser aperfeiçoados. Portanto, o perfil abrangente de metabólitos pode exigir a combinação e a integração de múltiplos métodos de extração. ${ }^{5,15,22}$ Além disso, o emprego de microtécnicas de extração também tem sido um grande atrativo para esse tipo de estudo. Métodos miniaturizados também apresentam eficiências de extração e reprodutibilidade satisfatórias, além de se apresentarem como métodos limpos com baixo consumo de solventes ou reutilizáveis.

Na etapa de processamento de dados em metabolômica, são encontrados problemas a serem superados desde a etapa de pré-processamento até a identificação metabólica. Primeiramente, o processamento de dados altamente eficaz e automático continua sendo uma tarefa difícil, principalmente nos casos em que as etapas preliminares precisam ser implementadas para um grande volume de dados. A identificação confiável de metabólitos desconhecidos a partir de dados complexos de espectros permanece um grande desafio e, embora surjam novos bancos de dados para a metabolômica microbiana, eles são limitados a espécies específicas. ${ }^{4,5}$ No entanto, uma mudança desse cenário vem ocorrendo e tem sido sustentada pelos avanços em técnicas instrumentais, principalmente na espectrometria de massas. Além disso, uma ferramenta que tem ganhado espaço e sendo empregada em diversos contextos é o molecular networking. A confiabilidade e funcionalidade dessa ferramenta tem sido grande atrativo para os pesquisadores da área de metabolômica, e no âmbito de identificação de metabólitos microbianos, ela possivelmente será cada vez mais explorada.

Na comunidade científica, muitas divergências ainda são encontradas quanto a uma abordagem metabolômica genuína. No âmbito de micro-organismos, foi possível observar que grande parte dos estudos não seguem à risca todo o fluxo de trabalho usualmente adotado em metabolômica, sendo muitas vezes apenas uma avaliação global dos metabólitos ou um perfil de metabólitos específicos. Apesar de serem encontrados estudos que avaliem as variações metabólicas frente a mudanças específicas, ainda existem muitos casos em que apenas uma exploração do perfil metabólico do micro-organismo é realizada, sendo esses estudos também de extrema importância para a compreensão de uma via metabólica específica.

\section{AGRADECIMENTOS}

Os autores agradecem a Fundação de Amparo à Pesquisa do Estado de São Paulo (FAPESP - Processo 2016/20547-2, Processo 2018/03670-0 e Processo 2017/24462-4) e a Coordenação de Aperfeiçoamento de Pessoal de Nível Superior (CAPES).

\section{REFERÊNCIAS}

1. Lin, C. Y.; Viant, M. R.; Tjeerdema, R. S.; J. Pestic. Sci. 2006, 31, 245.

2. Allen, J.; Davey, H. M.; Broadhurst, D.; Heald, J. K.; Rowland, J. J.; Oliver, S. G.; Kell, D. B.; Nat. Biotechnol. 2003, 21, 692. 
3. Patterson, A. D.; Li, H.; Eichler, G. S.; Krausz, K. W.; Weinstein, J. N.; Fornace, A. J.; Gonzalez, F. J.; Idle, J. R.; Anal. Chem. 2008, 80, 665.

4. Yi, L.; Dong, N.; Yun, Y.; Deng, B.; Ren, D.; Liu, S.; Liang, Y.; Anal. Chim. Acta 2016, 914, 17.

5. Xu, Y. J.; Wang, C.; Ho, W. E.; Ong, C. N.; TrAC - Trends Anal. Chem. 2014, 56, 37

6. Yang, S.; Hoggard, J. C.; Lidstrom, M. E.; Synovec, R. E. Em Metabolomics in Practice; Lammerhofer, M., Weckworth, W., eds.; Wiley: Hoboken, 2013.

7. Fiehn, O.; Plant Mol. Biol. 2002, 48, 155.

8. Goodacre, R.; Vaidyanathan, S.; Dunn, W. B.; Harrigan, G. G.; Kell, D. B.; Trends Biotechnol. 2004, 22, 245.

9. Wenk, M. R.; Lipidomics of host-pathogen interactions. FEBS Lett. 2006, 580, 5541 .

10. Boots, A. W.; Smolinska, A.; Van Berkel, J. J. B. N.; Fijten, R. R. R.; Stobberingh, E. E.; Boumans, M. L. L.; Moonen, E. J.; Wouters, E. F. M.; Dallinga, J. W.; Van Schooten, F. J.; J. Breath Res. 2014, 027106.

11. Brunelli, L.; Caiola, E.; Marabese, M.; Broggini, M.; Pastorelli, R.; Oncotarget 2014, 5, 4722.

12. Raamsdonk, L. M.; Teusink, B.; Broadhurst, D.; Zhang, N.; Hayes, A.; Walsh, M. C.; Berden, J. A.; Brindle, K. M.; Kell, D. B.; Rowland, J. J.; Westerhoff, H. V; Van Dam, K.; Oliver, S. G.; Nat. Biotechnol. 2001, 19, 45 .

13. Boroughs, L. K.; Deberardinis, R. J.; Nat. Cell Biol. 2015, 17, 351.

14. Peisl, B. Y. L.; Schymanski, E. L.; Wilmes, P.; Anal. Chim. Acta 2018, 1037, 13

15. Canuto, G.; Costa, J. L.; Cruz, P.; Souza, A.; Faccio, A.; Klassen, A.; Rodrigues, K.; Tavares, M.; Quim. Nova 2017, 41, 75.

16. Yang, S.; Hoggard, J. C.; Lidstrom, M. E.; Synovec, R. E.; J. Chromatogr. A 2013, 1317, 175.

17. Smart, K. F.; Aggio, R. B. M.; Van Houtte, J. R.; Villas-Bôas, S. G.; Nat. Protoc. 2010, 5, 1709

18. Dunn, W. B.; Ellis, D. I.; TrAC - Trends Anal. Chem. 2005, 24, 285.

19. Naz, S.; Vallejo, M.; García, A.; Barbas, C.; J. Chromatogr. A 2014, $1353,99$.

20. Kondakova, T.; Merlet-Machour, N.; Chapelle, M.; Preterre, D.; Dionnet, F.; Feuilloley, M.; Orange, N.; Duclairoir Poc, C.; Res. Microbiol. 2015, 166,1 .

21. Gravouil, K.; Ferru-Clément, R.; Colas, S.; Helye, R.; Kadri, L.; Bourdeau, L.; Moumen, B.; Mercier, A.; Ferreira, T.; Environ. Sci. Technol. 2017, 51, 5172 .

22. Beale, D. J.; Kouremenos, K. A.; Palombo, E. A.; Microbial Metabolomics, Springer International Publishing: Cham, 2016.

23. Khoomrung, S.; Wanichthanarak, K.; Nookaew, I.; Thamsermsang, O.; Seubnooch, P.; Laohapand, T.; Akarasereenont, P.; Front. Pharmacol. 2017, 8, 474.

24. Viant, M. R.; Kurland, I. J.; Jones, M. R.; Dunn, W. B.; Curr. Opin. Chem. Biol. 2017, 36, 64.

25. Pinu, F. R.; Villas-Boas, S. G.; Aggio, R.; Metabolites 2017, 7, 53.

26. Ząbek, A.; Junka, A.; Szymczyk, P.; Wojtowicz, W.; Klimek-Ochab, M.; Młynarz, P.; J. Basic Microbiol. 2017, 57, 428.

27. Carro, L.; Persson, T.; Pujic, P.; Alloisio, N.; Fournier, P.; Boubakri, H.; Pawlowski, K.; Normand, P.; Symbiosis 2016, 70, 37.

28. Johnson, W. M.; Kido Soule, M. C.; Kujawinski, E. B.; ISME J. 2016, 10, 2304.

29. Farrés, M.; Piña, B.; Tauler, R.; Metallomics 2016, 8, 790.

30. Nguyen, D. D.; Melnik, A. V.; Koyama, N.; Lu, X.; Schorn, M.; Fang, J.; Aguinaldo, K.; Lincecum, T. L.; Ghequire, M. G. K.; Carrion, V. J.; Cheng, T. L.; Duggan, B. M.; Malone, J. G.; Mauchline, T. H.; Sanchez, L. M.; Kilpatrick, A. M.; Raaijmakers, J. M.; De Mot, R.; Moore, B. S.; Medema, M. H.; Dorrestein, P. C.; Nat. Microbiol. 2016, 2, 1.

31. Villas-Bôas, S. G.; Mas, S.; Akesson, M.; Smedsgaard, J.; Nielsen, J.; Mass Spectrom. Rev. 2005, 24, 613.
32. Kapoore, R. V.; Coyle, R.; Staton, C. A.; Brown, N. J.; Vaidyanathan, S.; Analyst 2017, 142, 2038.

33. Wittmann, C.; Krömer, J. O.; Kiefer, P.; Binz, T.; Heinzle, E.; Anal. Biochem. 2004, 327, 135.

34. Lorenz, M. A.; Burant, C. F.; Kennedy, R. T.; Anal. Chem. 2011, 83, 3406.

35. Kim, J.; Kim, K. H.; Process Biochem. 2017, 57, 64.

36. Shi, Y.; Pan, C.; Auckloo, B. N.; Chen, X.; Chen, C. T. A.; Wang, K.; Wu, X.; Ye, Y.; Wu, B.; Appl. Microbiol. Biotechnol. 2017, 101, 1395.

37. Li, H.; Xia, X.; Li, X.; Naren, G.; Fu, Q.; Wang, Y.; Wu, C.; Ding, S.; Zhang, S.; Jiang, H.; Li, J.; Shen, J.; J. Proteome Res. 2015, 14, 1060.

38. Bo, T.; Liu, M.; Zhong, C.; Zhang, Q.; Su, Q.-Z.; Tan, Z.-L.; Han, P.-P.; Jia, S.-R.; J. Agric. Food Chem. 2014, 62, 4454.

39. Tredwell, G. D.; Aw, R.; Edwards-Jones, B.; Leak, D. J.; Bundy, J. G.; J. Ind. Microbiol. Biotechnol. 2017, 44, 413.

40. Pluskal, T.; Yanagida, M.; Cold Spring Harb. Protoc. 2016, 2016, 1044.

41. AlMasoud, N.; Xu, Y.; Trivedi, D. K.; Salivo, S.; Abban, T.; Rattray, N. J. W.; Szula, E.; AlRabiah, H.; Sayqal, A.; Goodacre, R.; Anal. Bioanal. Chem. 2016, 408, 7865.

42. Pomraning, K. R.; Wei, S.; Karagiosis, S. A.; Kim, Y. M.; Dohnalkova, A. C.; Arey, B. W.; Bredeweg, E. L.; Orr, G.; Metz, T. O.; Baker, S. E.; PLoS One 2015, 10, 1.

43. Anasontzis, G. E.; Kourtoglou, E.; Villas-Boâs, S. G.; Hatzinikolaou, D. G.; Christakopoulos, P.; Front. Microbiol. 2016, 7, 1.

44. Liu, M.; Zhong, C.; Wu, X. Y.; Wei, Y. Q.; Bo, T.; Han, P. P.; Jia, S. R.; Biochem. Eng. J. 2015, 101, 85.

45. Drapal, M.; Perez-Fons, L.; Wheeler, P. R.; Fraser, P. D.; J. Microbiol. Methods 2014, 106, 23.

46. Kim, S.; Lee, D. Y.; Wohlgemuth, G.; Park, H. S.; Fiehn, O.; Kim, K. H.; Anal. Chem. 2013, 85, 2169.

47. Lee, M. Y.; Kim, H. Y.; Lee, S.; Kim, J. G.; Suh, J. W.; Lee, C. H.; J. Microbiol. Biotechnol. 2015, 25, 1265.

48. Dunn, W. B.; Bailey, N. J. C.; Johnson, H. E.; Analyst 2005, 130, 606.

49. Soboń, A.; Szewczyk, R.; Różalska, S.; Długoński, J.; Int. Biodeterior. Biodegrad. 2018, 127, 130.

50. Spraker, J. E.; Sanchez, L. M.; Lowe, T. M.; Dorrestein, P. C.; Keller, N. P.; ISME J. 2016, 10, 2317.

51. Herman, N. A.; Kim, S. J.; Li, J. S.; Cai, W.; Koshino, H.; Zhang, W.; Nat. Commun. 2017, 8, 1514.

52. Weidt, S.; Haggarty, J.; Kean, R.; Cojocariu, C. I.; Silcock, P. J.; Rajendran, R.; Ramage, G.; Burgess, K. E. V.; Metabolomics 2016, 12, 1.

53. Pacini, T.; Fu, W.; Gudmundsson, S.; Chiaravalle, A. E.; Brynjolfson, S.; Palsson, B. O.; Astarita, G.; Paglia, G.; Anal. Chem. 2015, 87, 2593.

54. Mandelli, F.; Couger, M. B.; Paixão, D. A. A.; Machado, C. B.; Carnielli, C. M.; Aricetti, J. A.; Polikarpov, I.; Prade, R.; Caldana, C.; Paes Leme, A. F.; Mercadante, A. Z.; Riaño-Pachón, D. M.; Squina, F. M.; Extremophiles 2017, 21, 775.

55. Nizio, K. D.; Perrault, K. A.; Troobnikoff, A. N.; Ueland, M.; Shoma, S.; Iredell, J. R.; Middleton, P. G.; Forbes, S. L.; J. Breath Res. 2016, 10, 026008.

56. Rees, C. A.; Stefanuto, P.-H.; Beattie, S. R.; Bultman, K. M.; Cramer, R. A.; Hill, J. E.; J. Breath Res. 2017, 11, 036003.

57. Dunkel, T.; Gallego, de L.; S, E. L.; Schönsee, C. D.; Hesse, T.; Jochmann, M.; Wingender, J.; Denecke, M.; Water Res. 2016, 88, 510.

58. Salvador, Â. C.; Baptista, I.; Barros, A. S.; Gomes, N. C. M.; Cunha, Â.; Almeida, A.; Rocha, S. M.; PLoS One 2013, 8, e59338.

59. Rees, C. A.; Burklund, A.; Stefanuto, P.; Schwartzman, J. D.; Hill, J. E.; J. Breath Res. 2018, 12, 026001.

60. Barkal, L. J.; Theberge, A. B.; Guo, C.-J.; Spraker, J.; Rappert, L.; Berthier, J.; Brakke, K. A.; Wang, C. C. C.; Beebe, D. J.; Keller, N. P.; Berthier, E.; Nat. Commun. 2016, 7, 10610. 
61. Jousse, C.; Dalle, C.; Canet, I.; Lagrée, M.; Traïkia, M.; Lyan, B.; Mendes, C.; Sancelme, M.; Amato, P.; Delort, A.-M.; Metabolomics 2018, $14,11$.

62. Smedsgaard, J.; J. Chromatogr. A 1997, 760, 264.

63. Zhong, F.; Xu, M.; Schelli, K.; Rutowski, J.; Holmén, B. A.; Zhu, J. Ecotoxicol. Environ. Saf. 2017, 142, 164.

64. Shi, Y.; Pan, C.; Wang, K.; Chen, X.; Wu, X.; Chen, C. T. A.; Wu, B.; Environ. Microbiol. 2017, 19, 3606.

65. Bohni, N.; Hofstetter, V.; Gindro, K.; Buyck, B.; Schumpp, O.; Bertrand, S.; Monod, M.; Wolfender, J.-L.; Molecules 2016, 21, 370.

66. Lau, S. K. P.; Lam, C.-W.; Curreem, S. O. T.; Lee, K.-C.; Chow, W.-N.; Lau, C. C. Y.; Sridhar, S.; Wong, S. C. Y.; Martelli, P.; Hui, S.-W.; Yuen, K.-Y.; Woo, P. C. Y.; Cell Biosci. 2015, 5, 26.

67. Bose, U.; Hewavitharana, A. K.; Ng, Y. K.; Shaw, P. N.; Fuerst, J. A.; Hodson, M. P.; Mar. Drugs 2015, 13, 249.

68. De Lima, P. F.; Furlan, M. F.; De Lima Ribeiro, F. A.; Pascholati, S. F.; Augusto, F.; J. Sep. Sci. 2015, 38, 1924.

69. Rees, C. A.; Franchina, F. A.; Nordick, K. V.; Kim, P. J.; Hill, J. E.; J. Appl. Microbiol. 2017, 122, 785.

70. Johanningsmeier, S. D.; McFeeters, R. F.; Int. J. Food Microbiol. 2015, $215,40$.

71. Mousavi, F.; Gionfriddo, E.; Carasek, E.; Souza-Silva, E. A.; Pawliszyn, J.; Metabolomics 2016, 12, 169.

72. Rees, C. A.; Shen, A.; Hill, J. E.; J. Chromatogr. B 2016, 1039, 8.

73. Alves, Z.; Melo, A.; Figueiredo, A. R.; Coimbra, M. A.; Gomes, A. C.; Rocha, S. M.; PLoS One 2015, 10, e0143641.

74. Zhang, Q. H.; Zhou, L. Di; Chen, H.; Wang, C. Z.; Xia, Z. N.; Yuan, C. S.; TrAC - Trends Anal. Chem. 2016, 80, 57.

75. Souza Silva, E. A.; Risticevic, S.; Pawliszyn, J.; TrAC - Trends Anal. Chem. 2013, 43, 24.

76. Willers, C.; Jansen van Rensburg, P. J.; Claassens, S.; J. Appl. Microbiol. 2015, 118, 1251.

77. Theodoridis, G.; Gika, H. G.; Wilson, I. D.; Mass Spectrom. Rev. 2011, 47, 987.

78. Lee, T. H.; Chang, J. S.; Wang, H. Y.; Anal. Chem. 2013, 85, 2155.

79. Li, L.; Han, J.; Wang, Z.; Liu, J.; Wei, J.; Xiong, S.; Zhao, Z.; Int. J. Mol. Sci. 2014, 15, 10492.

80. Qiao, B.; Lu, H.; Cao, Y. X.; Chen, R.; Yuan, Y. J.; Eng. Life Sci. 2013, 13, 496.

81. Takeshita, T.; Ota, S.; Yamazaki, T.; Hirata, A.; Zachleder, V.; Kawano, S.; Bioresour. Technol. 2014, 158, 127.

82. ezanka, T.; Kolouchová, I.; Sigler, K.; Biochim. Biophys. Acta - Mol. Cell Biol. Lipids 2016, 1861, 1634.

83. Capusoni, C.; Rodighiero, V.; Cucchetti, D.; Galafassi, S.; Bianchi, D.; Franzosi, G.; Compagno, C.; Bioresour. Technol. 2017, 238, 281.

84. Singh, A.; MacKenzie, A.; Girnun, G.; Del Poeta, M.; J. Lipid Res. 2017, 58, 2017.

85. He, Y.; Zhang, P.; Huang, S.; Wang, T.; Ji, Y.; Xu, J.; Biotechnol. Biofuels 2017, 10, 275 .

86. Elahee Doomun, S.; Loke, S.; O'Callaghan, S.; Callahan, D. A.; Metabolites 2016, 6, 42.

87. Kumar, M.; Morya, R.; Gnansounou, E.; Larroche, C.; Thakur, I. S.; Bioresour. Technol. 2017, 243, 893.

88. Fu, Z.; Verderame, T. D.; Leighton, J. M.; Sampey, B. P.; Appelbaum, E. R.; Patel, P. S.; Aon, J. C.; Microb. Cell Fact. 2014, 13, 32.

89. Sasaki, D.; Sasaki, K.; Tsuge, Y.; Morita, M.; Kondo, A.; Bioresour. Technol. 2014, 172, 83.

90. Wolfender, J.-L.; Marti, G.; Thomas, A.; Bertrand, S.; J. Chromatogr. A 2015, 1382, 136.

91. Dallüge, J.; Beens, J.; Brinkman, U. A. T.; J. Chromatogr. A 2003, 1000, 69.

92. Rees, C. A.; Nordick, K. V.; Franchina, F. A.; Lewis, A. E.; Hirsch, E. B.; Hill, J. E.; Metabolomics 2017, 13, 18.
93. Mohler, R. E.; Dombek, K. M.; Hoggard, J. C.; Young, E. T.; Synovec, R. E.; Anal. Chem. 2006, 78, 2700.

94. Aldridge, B. B.; Rhee, K. Y.; Curr. Opin. Microbiol. 2014, 19, 90.

95. Triebl, A.; Hartler, J.; Trötzmüller, M.; C. Köfeler, H.; Lipidomics: Biochim. Biophys. Acta - Mol. Cell Biol. Lipids 2017, 1862, 740.

96. Tripathy, K.; J. Comput. Sci. Syst. Biol. 2012, 04, 93.

97. Milker, S.; Goncalves, L. C. P.; Fink, M. J.; Rudroff, F.; Front. Microbiol. 2017, 8, 1.

98. Hunter, J. E.; Frada, M. J.; Fredricks, H. F.; Vardi, A.; Van Mooy, B. A. S.; Front. Mar. Sci. 2015, 2, 1.

99. Zawadzka, K.; Bernat, P.; Felczak, A.; Lisowska, K.; Environ. Sci. Pollut. Res. 2015, 22, 19658

100. Feng, Y.; Zhao, Y.; Guo, Y.; Liu, S.; Water Res. 2018, 128, 402.

101. Stopka, S. a; Shrestha, B.; Maréchal, E.; Falconet, D.; Vertes, A.; Analyst 2014, 139, 5945.

102. Groessl, M.; Graf, S.; Knochenmuss, R.; Analyst 2015, 140, 6904.

103. Zuñiga, C.; Zaramela, L.; Zengler, K.; Microb. Biotechnol. 2017, 10, 1500

104. Perez-Garcia, O.; Lear, G.; Singhal, N.; Front. Microbiol. 2016, 7, 673. 105. von Kamp, A.; Klamt, S.; Nat. Commun. 2017, 8, 15956.

106. Schenk, E. R.; Nau, F.; Thompson, C. J.; Tse-Dinh, Y. C.; FernandezLima, F.; J. Mass Spectrom. 2015, 50, 88.

107. Calvano, C. D.; Italiano, F.; Catucci, L.; Agostiano, A.; Cataldi, T. R. I.; Palmisano, F.; Trotta, M.; BioMetals 2014, 27, 65.

108. Vitale, R.; Roine, E.; Bamford, D. H.; Corcelli, A.; Biochim. Biophys. Acta - Mol. Cell Biol. Lipids 2013, 1831, 872.

109. de Bruijn, I.; Cheng, X.; de Jager, V.; Expósito, R. G.; Watrous, J.; Patel, N.; Postma, J.; Dorrestein, P. C.; Kobayashi, D.; Raaijmakers, J. M.; BMC Genomics 2015, 16, 991.

110. Ho, Y.-N.; Shu, L.-J.; Yang, Y.-L.; Wiley Interdiscip. Rev.: Syst. Biol. Med. 2017, 9, e1387.

111. Caprioli, R. M.; Farmer, T. B.; Gile, J.; Anal. Chem._1997, 69, 4751.

112. Andersson, M.; Groseclose, M. R.; Deutch, A. Y.; Caprioli, R. M.; Nat. Methods 2008, 5, 101.

113. Shih, C.-J.; Chen, P.-Y.; Liaw, C.-C.; Lai, Y.-M.; Yang, Y.-L.; Nat. Prod. Rep. 2014, 31, 739.

114. Sandonato, B. B.; Santos, V. G.; Luizete, M. F.; Bronzel, J. L.; Eberlin, M. N.; Milagre, H. M. S.; J. Braz. Chem. Soc. 2017, 28, 521.

115. Esquenazi, E.; Coates, C.; Simmons, L.; Gonzalez, D.; Gerwick, W. H.; Dorrestein, P. C.; Mol. Biosyst. 2008, 4, 562.

116. Simmons, T. L.; Coates, R. C.; Clark, B. R.; Engene, N.; Gonzalez, D.; Esquenazi, E.; Dorrestein, P. C.; Gerwick, W. H.; Proc. Natl. Acad. Sci. U. S. A. 2008, 105, 4587.

117. Lobete, M. M.; Fernandez, E. N.; Van Impe, J. F. M.; Front. Microbiol. 2015, 6,1 .

118. Weisener, C. G.; Reid, T.; Surf. Interface Anal. 2017, 49, 1416.

119. Sandrin, T. R.; Demirev, P. A.; Mass Spectrom. Rev. 2018, 37, 321.

120. Ho, Y.-N.; Shu, L.-J.; Yang, Y.-L.; Wiley Interdiscip. Rev.: Syst. Biol. Med. 2017, 9, e1387.

121. Luzzatto-Knaan, T.; Melnik, A. V.; Dorrestein, P. C.; Analyst 2015, 140, 4949.

122. Krastanov, A.; Biotechnol. Biotechnol. Equip. 2010, 24, 1537.

123. Misra, B. B.; van der Hooft, J. J. J.; Electrophoresis 2016, 37, 86.

124. Metabolomics: From Fundamentals to Clinical Applications; Sussulini, A., org.; Springer International Publishing: Cham, 2017.

125. Coble, J. B.; Fraga, C. G.; J. Chromatogr. A 2014, 1358, 155.

126. Castillo, S.; Gopalacharyulu, P.; Yetukuri, L.; Oreši, M.; Chemom. Intell. Lab. Syst. 2011, 108, 23.

127. Wei, X.; Sun, W.; Shi, X.; Koo, I.; Wang, B.; Zhang, J.; Yin, X.; Tang, Y.; Bogdanov, B.; Kim, S.; Zhou, Z.; McClain, C.; Zhang, X.; Anal. Chem. 2011, 83, 7668 .

128. Duran, A. L.; Yang, J.; Wang, L.; Sumner, L. W.; Bioinformatics 2003, 19,2283 
129. Hiller, K.; Hangebrauk, J.; Jäger, C.; Spura, J.; Schreiber, K.; Schomburg, D.; Anal. Chem. 2009, 81, 3429.

130. Broeckling, C. D.; Reddy, I. R.; Duran, A. L.; Zhao, X.; Sumner, L. W.; Anal. Chem. 2006, 78, 4334.

131. Allmann, S.; Mazet, M.; Ziebart, N.; Bouyssou, G.; Fouillen, L.; Dupuy, J.-W.; Bonneu, M.; Moreau, P.; Bringaud, F.; Boshart, M.; PLoS One 2014, 9, e114628.

132. Meissner-Roloff, R. J.; Koekemoer, G.; Warren, R. M.; Loots, D. T.; Metabolomics 2012, 8, 1194.

133. Lee, L. C.; Liong, C.-Y.; Jemain, A. A.; Analyst 2018, 143, 3526.

134. Liu, Y.; Zhang, J.; Nie, H.; Dong, C.; Li, Z.; Zheng, Z.; Bai, Y.; Liu, H.; Zhao, J.; Anal. Chem. 2014, 86, 7096.

135. Kouremenos, K. A.; Beale, D. J.; Antti, H.; Palombo, E. A.; $J$. Chromatogr. B 2014, 966, 179.

136. Chin, E. L.; Mishchuk, D. O.; Breksa, A. P.; Slupsky, C. M.; J. Agric. Food Chem. 2014, 62, 6585.

137. Szewczyk, R.; Kuśmierska, A.; Bernat, P.; Chemosphere 2018, 190, 174.

138. Zhai, P.; Yang, L.; Guo, X.; Wang, Z.; Guo, J.; Wang, X.; Zhu, H.; BMC Bioinformatics 2017, 18, 1.
139. Meier, R.; Ruttkies, C.; Treutler, H.; Neumann, S.; J. Biotechnol. 2017, 261, 137.

140. Zhai, P.; Yang, L.; Guo, X.; Wang, Z.; Guo, J.; Wang, X.; Zhu, H.; Kind, T.; Wohlgemuth, G.; Lee, D. Y.; Lu, Y.; Palazoglu, M.; Shahbaz, S.; Fiehn, O.; BMC Bioinformatics 2017, 81, 1.

141. Marco-Ramell, A.; Palau-Rodriguez, M.; Alay, A.; Tulipani, S.; UrpiSarda, M.; Sanchez-Pla, A.; Andres-Lacueva, C.; BMC Bioinformatics 2018, $19,1$.

142. Olivon, F.; Roussi, F.; Litaudon, M.; Touboul, D.; Anal. Bioanal. Chem. 2017, 409, 5767.

143. Yang, J. Y.; Sanchez, L. M.; Rath, C. M.; Liu, X.; Boudreau, P. D.; Bruns, N.; Glukhov, E.; Wodtke, A.; de Felicio, R.; Fenner, A.; Wong, W. R.; Linington, R. G.; Zhang, L.; Debonsi, H. M.; Gerwick, W. H.; Dorrestein, P. C.; J. Nat. Prod. 2013, 76, 1686.

144. German, J. B.; Gillies, L. A.; Smilowitz, J. T.; Zivkovic, A. M.; Watkins, S. M.; Curr. Opin. Lipidol. 2007, 18, 66. 